\author{
UNIVERSIDADE ESTADUAL PAULISTA \\ FACULDADE DE MEDICINA VETERINÁRIA E ZOOTECNIA
}

CONTAMINAÇÃO AMBIENTAL POR GEO-HELMINTOS EM PRAÇAS DO

MUNICÍPIO DE BOTUCATU, SÃO PAULO

GILSON AVELINO PROVIDELO

Botucatu - SP

2019 
CONTAMINAÇÃO AMBIENTAL POR GEO-HELMINTOS EM PRAÇAS DO MUNICÍPIO DE BOTUCATU, SÃO PAULO

\author{
Dissertação apresentada junto ao \\ Programa de Pós-Graduação em \\ Medicina Veterinária para obtenção do \\ título de Mestre \\ Orientador(a): Prof ${ }^{a}$. Ass. Dr ${ }^{\text {a }}$ Elizabeth \\ Moreira dos Santos Schmidt \\ Co-Orientador: Prof. $\mathrm{Dr}^{\circ}$ Vamilton \\ Alvares Santarém
}

Botucatu - SP 
FICHA CATALOGRÁficA ELABORAdA PELA SEÇÃO tÉC. AQUis. tRATAMENTO DA INFORM. DIVISÃO TÉCNICA DE BIBLIOTECA E DOCUMENTAÇÃO - CÂMPUS DE BOTUCATU - UNESP

BIBLIOTECÁRIA RESPONSÁVEL: ROSANGELA APARECIDA LOBO-CRB $8 / 7500$

Providelo, Gilson Avelino.

Contaminação ambiental por Geo-Helmintos em praças do

Município de Botucatu, São Paulo / Gilson Avelino Providelo.

- Botucatu, 2019

Dissertação (mestrado) - Universidade Estadual Paulista "Júlio de Mesquita Filho", Faculdade de Medicina Veterinária e Zootecnia

Orientador: Elizabeth Moreira dos Santos Schmidt

Coorientador: Vamilton Alvares Santarém

Capes: 50502042

1. Solos - Contaminação. 2. Helmintos. 3. Toxocara. 4. Zoonoses. 5. Poluição ambiental.

Palavras-chave: Contaminação do solo; Toxocara; geo-helmintos; zoonose. 
Nome do Autor: Gilson Avelino Providelo

Título: CONTAMINAÇÃO AMBIENTAL POR GEO-HELMINTOS EM PRAÇAS DO MUNICÍPIO DE BOTUCATU, SÃO PAULO

\section{COMISSÃO EXAMINADORA}

Prof $^{a}{ }^{\mathrm{D}}{ }^{\mathrm{a}}$ Elizabeth Moreira dos Santos Schmidt

Presidente e Orientadora

Departamento Clínica Veterinária

FMVZ - UNESP - Botucatu

Prof.Dr. Cassiano Victória

Membro

Departamento de Higiene Veterinária e Saúde Pública

FMVZ - UNESP - Botucatu

Prof $^{\mathrm{a}} \mathrm{Dr}^{\mathrm{a}}$. Lucilene Delazari dos Santos

Membro

Centro de Estudos de Venenos e Animais Peçonhentos - CEVAP

Data da Defesa: 30 de Abril de 2019. 
Àquela que sempre acreditou em mim mais do que eu mesmo. Que segurava a minha mão até que eu dormisse e, mais de 30 anos depois, ainda não soltou!

À mulher que sempre me falou que eu poderia ser quem eu quisesse, e que o conhecimento é a única coisa que ninguém vai conseguir me tomar

Dedico este trabalho à minha mãe, D. Neuzete! 


\section{AGRADECIMENTOS}

Ao curso de Pós-Graduação em Medicina Veterinária da Faculdade de Medicina Veterinária e Zootecnia (FMVZ), UNESP, câmpus de Botucatu, por esta oportunidade que me permitiu crescer e amadurecer muito.

A minha orientadora Elizabeth Moreira dos Santos Schmidt por toda a dedicação, tempo e paciência. Por me fazer crescer e me incentivar a fazer sempre o meu melhor.

Ao meu co-orientador Prof. Dr Vamilton Alvares Santarém, por toda atenção e ajuda na padronização da técnica, pois sem este auxilio não seria possível a realização deste trabalho

Ao Prof. Dr. Cassiano Victória pela ajuda no planejamento inicial do projeto e colaboração no exame de qualificação e participação na banca de defesa desta dissertação.

Ao Prof. Dr. José Carlos Pantoja pela ajuda com as análises estatísticas.

Aos meus pais, Neuzete e Orlando, por serem a minha base forte e a minha referência de vida. Por me ensinar desde cedo preciosos valores que hoje formam meu caráter. Pela presença constante em todas as minhas decisões.

Ao meu irmão Edilson, pelo seu incentivo e ajuda que sempre me motivou a seguir em frente.

Aos meus amigos Dr. Washington Takashi Kano, Pamella Gomes, Martha Aparecida Augusto, Ana Paula Batista, Lívia Quadros, Patricia Reis Campanuci e Danilo Jorge que me acompanharam por toda essa árdua caminhada rumo à uma nova fase de vida.

Em especial, com muito carinho, eu agradeço a minha amiga e companheira de caminhada, Raphaela M. de Oliveira, minha "irmã de mestrado", que me ajudou não só com as análises laboratoriais, mas, com a convivência, laços de amizade criados, e foram fundamentais para me manter firme nos momentos de desânimo. 


\section{LISTA DE TABELAS}

\section{CAPÍTULO 1}

Tabela 1- Prevalência de cães positivos para Toxocara spp. em diversas unidades federativas (UF) do Brasil.

\section{CAPÍTULO 2}

Tabela 1- Frequência da presença de ovos Toxocara spp. em amostras de solo nos momentos I (2017) e II (2018), nas praças do município de Botucatu, SP.

Tabela 2- Frequência da presença de ovos ancilostomídeos em amostras de solo nos momentos I (2017) e II (2018), nas praças do município de Botucatu,SP.

Tabela 3- Dados de temperatura média, precipitação acumulada e umidade relativa do ar dos nos momentos I (2017) e II (2018), do município de Botucatu, SP

Tabela 4- Análise univariada dos fatores de risco para presença de ovos de Toxocara spp. em amostras de solo de praças de Botucatu, SP

Tabela 5- Variável de risco (presença de fezes) associada à presença de ovos Toxocara spp. nas amostras de solo das praças do município de Botucatu, SP

ANEXO

Tabela 1- Praças do município de Botucatu avaliadas nos momento I (2017).

Tabela 2- Praças do município de Botucatu avaliadas no momento II (2018), 


\section{LISTA DE FIGURAS}

Figura 1- Mapa setorizado do município de Botucatu, SP

51

Figura 2- Mapa com os pontos positivos para ovos de Toxocara spp. no momento I.

Figura 3- Mapa com os pontos positivos para ovos de Toxocara spp. (pontos azuis) e ovos de ancilostomídeos (pontos vermelhos) no momento II 


\section{SUMÁRIO}

Página

RESUMO

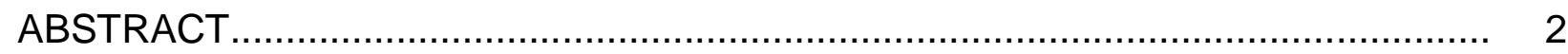

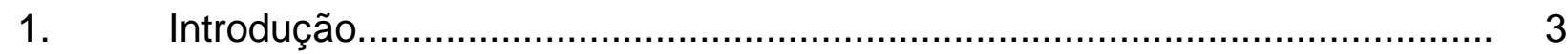

\section{CAPITULO 1}

2. REVISÃO BIBLIOGRÁFICA ........................................................ 5

2.1. Principais espécies de geo-helmintos ……........................................... 6

2.2. Geo-helmintos no mundo............................................................... 8

2.3. Geo-helmintos no Brasil.................................................................... 9

2.4. Geo-helmintos no local de estudo....................................................... 9

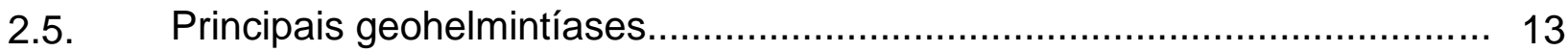

2.5.1 Larva Migrans Visceral Clássica (LMV)............................................... 14

2.5.2 Larva Migrans Visceral Oculta (LMVO) ................................................. 14

2.5.3 Larva Migrans Ocular (LMO) ............................................................ 14

2.5.4 Larva Migrans Cutânea.......................................................................... 15

2.6 Métodos laboratoriais de diagnóstico de geo-helmintos.............................. 16

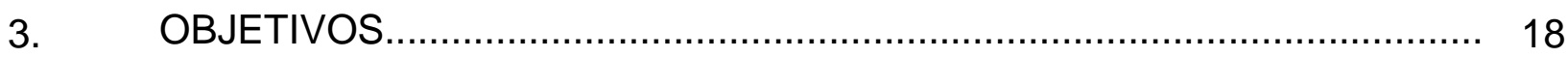

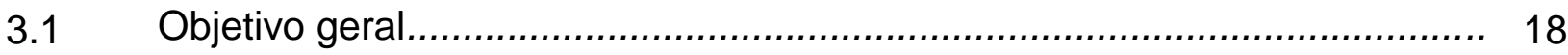

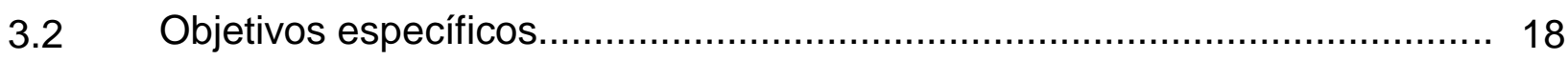

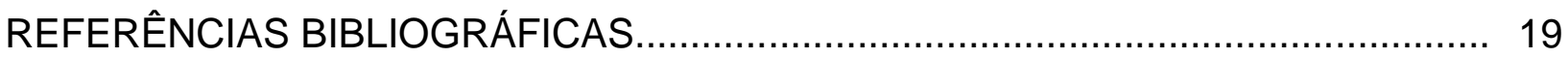

CAPITULO $2 \quad 29$

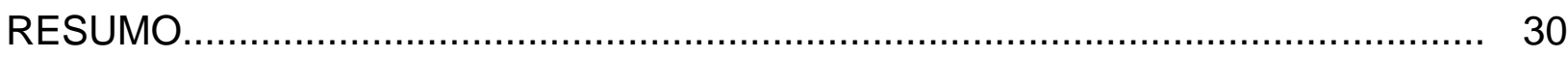

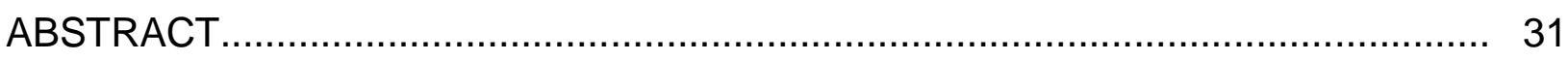

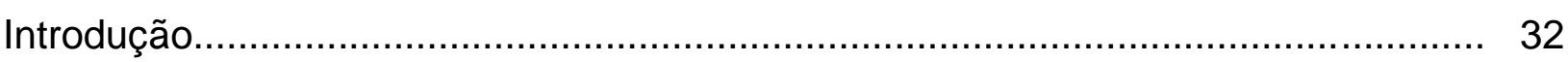

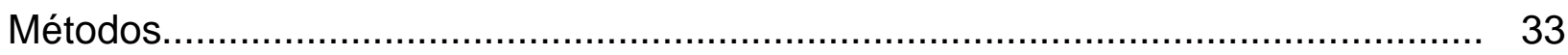

Resultados e Discussão................................................................................... 36

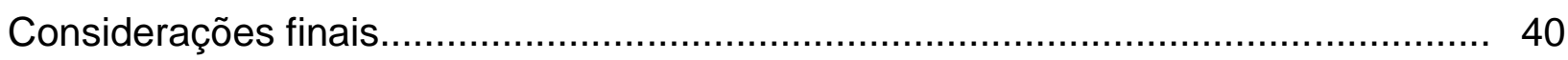

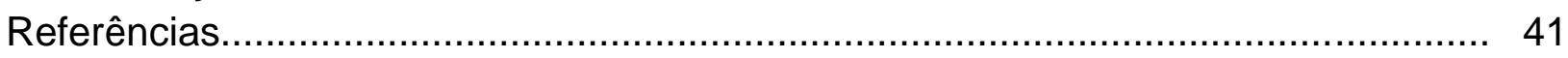

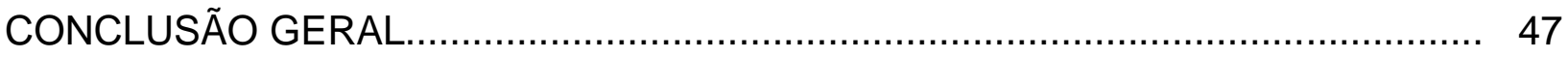

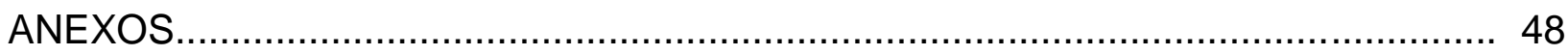




\section{PROVIDELO, G.A. Contaminação ambiental por geo-helmintos em praças do município de Botucatu,São Paulo. Botucatu, 2019.}

Dissertação (Mestrado) - Faculdade de Medicina Veterinária e Zootecnia, Campus de Botucatu, Universidade Estadual Paulista.

\section{RESUMO}

Os geo-helmintos são um grupo de parasitas em que parte do ciclo evolutivo ocorre necessariamente no solo, que desempenha o papel de fonte de infecção. O solo pode ser responsável pela transmissão das geohelmintíases, principalmente quando o local é compartilhado por animais e seres humanos, como em parques e/ou praças públicas. Em relação aos geohemintos de potencial zoonótico, destacam-se os gêneros Toxocara e Ancylostoma. Entretanto, outros parasitos intestinais, como Trichuris spp. e Strongyloides spp., que possuem parte de seu ciclo biológico no solo, também desempenham importante papel na contaminação de ambientes públicos. Desta forma o objetivo deste trabalho foi investigar a contaminação do solo por geo-helmintos em praças do município de Botucatu-SP, identificando a prevalência dos principais gêneros e sua ocorrência em praças de diferentes áreas do município. As praças foram catalogadas e distribuídas entre as regiões administrativas (norte, sul, leste, oeste e central). As coletas foram realizadas em dois momentos: momento I (de outubro a dezembro de 2017) e momento II (de fevereiro a março de 2018). No presente trabalho foram coletadas amostras de solo e avaliadas por meio das técnicas de centrífugosedimentação, centrífugo-flutuação com sulfato de zinco, e o método de Baermann-Moraes na busca por ovos e larvas de geo-helmintos. A partir das análises das amostras do solo obtidas nas praças estudadas, foram observados ovos do gênero Toxocara e ovos de ancilostomídeos, sendo este último encontrado somente nas coletas realizadas no momento II. Os resultados obtidos no presente estudo demonstraram que o risco de contaminação de seres humanos por ovos de Toxocara spp. esteve presente, pois este foi o geo-helminto mais prevalente. O principal fator de risco observado e relacionado à presença de ovos de Toxocara spp. nos locais investigados, foi a presença de fezes de animais, em virtude do livre acesso dos animais em locais públicos, promovendo um ambiente favorável ao desenvolvimento do ciclo do parasita e uma possível contaminação dos seres humanos. Neste cenário, políticas de saúde pública são necessárias para a diminuição dos focos de Toxocara spp. e evitar a contaminação da população humana que frequenta esses locais. Desta forma, além dos médicos veterinários, a comunidade deve exercer o papel de agente de saúde, combinando abordagens para prevenir a contaminação do solo por geohelmintos e controlar as geohelmintíases na população.

Palavras-chave: contaminação do solo; geo-helmintos; Toxocara spp; zoonose. 
PROVIDELO, G.A. Environmental contamination by geohelminths in squares of the municipality of Botucatu, São Paulo. Botucatu, 2019. Dissertação (Mestrado) - Faculdade de Medicina Veterinária e Zootecnia, Campus de Botucatu, Universidade Estadual Paulista.

\section{ABSTRACT}

Geohelminths are a group of parasites in which part of the life cycle necessarily occurs in the soil, playing a role as a source of infection. Soil may be responsible for the transmission of geohelminthiasis, especially when the site is shared by animals and humans, such as in parks and/or public squares. Regarding geohelminths of zoonotic potential, we highlight the genera Toxocara and Ancylostoma. However, other intestinal parasites, such as Trichuris spp. and Strongyloides spp., which also have part of their biological cycle in the soil, also play an important role in the contamination of public environments. This study aimed to investigate the soil contamination by geohelminths in squares of the municipality of Botucatu-SP, identifying the prevalence of the main genera and their occurrence in squares of different areas of the municipality. The squares were cataloged and distributed among administrative regions (north, south, east, west, and central). The samples were carried out in two time point: I (from October to December 2017) and II (from February to March 2018). In this study soil samples were collected and evaluated by means of centrifugalsedimentation techniques, zinc sulfate centrifugal flotation , and the BaermannMoraes method searching for geohelminths eggs and larvaes. From the soil samples obtained in the studied squares, eggs of the genus Toxocara and eggs of Ancylostomatoidea were observed, being the latter only found in the samples obtained at time point II. The results of in the present study demonstrated that the risk of human contamination by Toxocara spp. exists because it was the most prevalent geohelminth and the main risk factor observed and related to the presence of Toxocara spp. eggs, was the presence of animal feces in the evaluated environments, which could lead to the development of the parasite cycle and possible contamination of humans. In this way public health policies are necessary to reduce and to avoid the contamination of the human population that have access to these places. Therefore, in addition to veterinarians, the community should play the role of health agents, combining approaches to prevent soil contamination by geohelminths and controlling geohelminthiasis in the population.

Keywords: Soil contamination; geohelminths; Toxocara spp.; zoonosis. 


\section{INTRODUÇÃO}

Os geo-helmintos são um grupo de parasitas em que parte do ciclo evolutivo ocorre necessariamente no solo, que desempenha o papel de fonte de infecção, propiciando o desenvolvimento dos estágios infectantes (MOTA et al., 2018). O solo pode ser responsável pela transmissão das geo-helmintíases, principalmente quando o local é compartilhado por animais e seres humanos, como em parques e/ou praças públicas. O livre acesso de cães e gatos a esses locais, onde geralmente depositam suas fezes, podem aumentar probabilidade de contaminação do solo por ovos e larvas de geo-helmintos (CASSENOTE et al., 2011).

Todos os geo-helmintos sofrem influêcia das alterações ambientais no solo e clima da região. A sobrevivência e o desenvolvimento dos estágios infectantes dependem da temperatura e umidade ambientais além das características do solo (CHIEFFI et al., 2015).

O clima do município de Botucatu é classificado pelo método de Köppen (ROLIM et al., 2007; KÖPPEN E GEIGER, 1928), como sendo Cfa (Clima subtropical úmido), clima que possui quatro estações bem definidas: um verão relativamente quente, um outono com temperaturas gradativamente mais baixas comparadas ao verão, um inverno mais frio e uma primavera com temperaturas gradativamente mais altas comparadas ao inverno. Quanto aos índices pluviométricos, os períodos mais secos ocorrem nos meses de abril, julho e agosto, e o período chuvoso se concentra nos meses de primaveraverão, com índices pluviométricos relativamente elevados (CUNHA, 2009).

A associação da poluição ambiental, condições sanitárias deficientes e o comportamento humano desempenham um papel importante na transmissão dos geo-helmintos, contribuindo diretamente na disseminação, seja por transmissão ativa ou passiva (ULUKANLIGIL et al., 2001).

As infecções produzidas por geo-helmintos ocorrem em praticamente todas as zonas tropicais e subtropicais do planeta devido a uma multiplicidade de fatores, constituindo um relevante problema de saúde pública para a população de países em desenvolvimento, como o Brasil (WHO, 2017). 
No Brasil, pelas acentuadas desigualdades sócio-econômicas, aliadas ao processo desordenado de urbanização, as geo-hemintíases se caracterizam como um problema em saúde pública, principalmente em comunidades carentes de saneamento básico e higiene individual deficiente (FONSECA et al., 2010).

Em relação aos geo-hemintos de potencial zoonótico, destacam-se os gêneros Toxocara e Ancylostoma. Entretanto, outros parasitos intestinais, como Trichuris spp. e Strongyloides spp., que possuem parte de seu ciclo biológico no solo, também desempenham importante papel na contaminação de ambientes públicos (PRESTES et al., 2012). Desta forma o objetivo deste trabalho foi investigar a contaminação do solo por geo-helmintos em praças do município de Botucatu-SP, identificando a prevalência dos principais gêneros e sua ocorrência em praças de diferentes áreas do município. 


\section{CAPÍTULO 1}

\section{REVISÃO DE LITERATURA}

Os geo-helmintos são um grupo de parasitas que necessitam que parte do ciclo evolutivo ocorra no solo, pois proporciona condições adequadas para o desenvolvimento dos ovos e/ou a manutenção da viabilidade das larvas até o contato com um novo hospedeiro. As espécies geo-hemínticas têm grande relevância em saúde pública, devido à resistência das suas formas infectantes (ovos e larvas) no ambiente (CHIEFFI E AMATO NETO, 2003; JIA et al., 2012; MOTA et al., 2018).

As infecções por geo-helmintos apresentam capacidade relevante de causar morbidade e incapacidade, mas com baixa mortalidade. No entanto, apesar de sua importância clínica, não são doenças de notificação compulsória. Entre os sinais clínicos estão a desnutrição, anemia ferropriva, síndrome de má absorção, obstrução intestinal, disenteria crônica, prolapso retal, complicações respiratórias e baixo ganho de peso. Nos quadros crônicos as geo-helmintíases apresentam-se como doenças insidiosas e debilitantes, especialmente para crianças (HOTEZ e KAMATH , 2009; OJHA et al., 2013).

A elevada prevalência associada à ampla distribuição geográfica dos geo-helmintos, conferem às geo-helmintíases uma posição relevante entre os principais problemas de saúde pública da população, especialmente a mais carente. As infecções geohelmínticas são particularmente frequentes entre populações que vivem em países de baixa e média renda, sendo um grande problema de saúde pública (HOSTE, 2001; FONSECA et al., 2010).

Entre os diversos geo-helmintos, destacam-se os ascarídeos (Ascaris spp. e Toxocara spp.), ancilostomídeos (Ancylostoma spp.), tricurídeos (Trichuris spp.) e o Strongyloides stercoralis. São frequentemente encontrados co-infectando o mesmo indivíduo, especialmente crianças em países em desenvolvimento (HOTEZ et al., 2006). 
Os ovos de ascarídeos e tricurídeos se desenvolvem melhor nos solos argilosos, nas camadas mais profundas. Este tipo de solo mantém a temperatura e principalmente, a umidade, necessária para o desenvolvimento e manutenção dos ovos, que apresentam vulnerabilidade a ação direta da luz solar (CROMPTON, 2001).

Ao contrário dos ascarídeos e tricurídeos, os ovos de ancilóstomideos eclodem no solo e dão origem a larvas de primeiro estágio, que se transformam em larvas infectantes sob condições ideais de temperatura $\left(20-30^{\circ} \mathrm{C}\right)$, sombreamento e umidade adequados. Os ancilostomídeos são mais prevalentes em solos arenosos, pois a estrutura desses solos, mais permeáveis do que os argilosos, com partículas maiores e os poros mais contínuos, favorece a migração das larvas (CROMPTON, 2001; CHIEFFI E AMATO NETO, 2003).

\subsection{Principais espécies de geo-helmintos}

A importância desses parasitas é frequentemente subestimada por médicos veterinários e o público em geral, embora Toxocara spp. e Ancylostoma spp. sejam os geo-helmintos mais importantes, em termos de distribuição geográfica e importância clínica (GORDON et al., 2017).

O gênero de geo-helminto zoonótico mais prevalente mundialmente é o Toxocara, devido à resistência dos ovos dos ascarídeos no solo, mesmo em condições adversas (resistindo a produtos químicos, variações de temperatura e de umidade). Além disso, a viabilidade dos ovos persiste por anos (KIRCHHEIMER, 2008; TRAVERSA et al., 2014).

O gênero Ancylostoma pode causar diferentes distúrbios cutâneos, entéricos e pulmonares, sendo a larva migrans cutânea (LMC) a principal patologia causada por este geo-helminto (SANTARÉM et al., 2004; TRAVERSA et al., 2014). Em cães, A. caninum, A. braziliense, A. ceylanicum e Uncinaria stenocephala são os principais espécies de ancilostomídeos, enquanto $A$. tubaeforme, A. braziliense e U. stenocephala parasitam felinos (ANDERSON, 2000; WEESE e FULFORD, 2011). 
No entanto, existem outras espécies importantes de geo-helmintos como Trichuris spp. e o $S$. stercoralis. Embora tenham suas prevalências negligenciadas podem estar envolvidos na contaminação de ambientes públicos (PRESTES et al., 2012).

Os tricurídeos apresentam distribuição mundial de forma semelhante aos ascarídeos. No entanto, os ovos dos Trichuris são consideravelmente mais sensíveis às mudanças das condições climáticas (ACHA E SZYFRES, 2003; WHO, 2017).

No Brasil, existem poucas investigações sobre a prevalência da tricuríase canina, porém em um dos poucos estudos sobre este geo-helminto, especialmente na região de Botucatu, Torrico et al. (2008) encontraram uma prevalência de 2,17\% em fezes de cães, recebidas no Laboratório de Enfermidades Parasitárias dos Animais da FMVZ-UNESP.

Em relação ao gênero Strongyloides, a espécie mais prevalente em seres humanos, cães e outras espécies é o $S$. stercoralis e tem sido objeto de pesquisa devido ao seu complexo ciclo biológico (ANDERSON, 2000; THAMSBORG et al., 2017).

O S. stercoralis apresenta distribuição cosmopolita, exceto nos extremos norte e sul, mas a sua prevalência é subestimada quando comparada a outros geo-helmintos. As informações sobre sua prevalência ainda são escassas (SCHÄR et al., 2013).

Uma preocupação primária com infecções por $S$. stercoralis em cães é o potencial zoonótico. O S. stercoralis pode se adaptar do ser humano para o cão, alterando sua virulência (capacidade autoinfecção e hiperinfecção) e caminhos migratórios e disseminação no hospedeiro. No entanto, no caso das cepas caninas adaptando-se ao ser humano, o cão poderia representar um risco significativo para a saúde humana. Quanto ao potencial zoonótico, assim como a disseminação do Strongyloides em gatos, são necessárias novas pesquisas (JALETA et al., 2017, THAMSBORG et al, 2017).

A existência de ovos e/ou larvas geo-helmintos no solo representa riscos potenciais para a população, pois estes resistem a condições 
meteorológicas adversas e agentes químicos. Assim, a contaminação do solo pode ser um indicador mais direto da infecção por geo-helmintos na população humana, por isso, estudos têm sido realizados nos últimos anos para determinar a prevalência de ovos de geo-helmintos nos parques, playgrounds e praias (BLASZKOWSKA et al. 2011; BOJAR e KAPLEC, 2012; MOURA et al., 2013; TRAVERSA et al., 2014; MOTA et al., 2018).

Tanto os cães e gatos errantes, como os domiciliados, guiados por seus tutores, defecam em áreas públicas e o não recolhimento das fezes pode implicar em um problema de saúde pública, o que desempenha um importante papel epidemiológico, como fonte para contaminação ambiental por geohelmintos (SCAINI et al., 2003).

\subsection{Geo-helmintos no mundo}

A prevalência dos geo-helmintos e suas formas infectantes sofrem influência das condições ambientais, sejam elas naturais, como características do solo e clima de determinada região, ou por modificações introduzidas pela atividade humana. Entretanto, também envolve fatores socioeconômicos, principalmente nas populações que residem em regiões de precárias condições de saneamento. Ademais, o processo crescente de urbanização observado atualmente, com a formação de grandes aglomerados de pessoas nas periferias, favorece a contaminação e ambiental por esses parasitas (CHIEFFI, 2015; ETEWA et al., 2016).

Segundo estimativas da Organização Mundial de Saúde (WHO, 2018) mais de 1,5 bilhão de pessoas, ou $24 \%$ da população mundial, apresenta infecções por algum geo-helminto. As infecções são amplamente distribuídas em áreas tropicais e subtropicais, com as maiores prevalências ocorrendo na África subsaariana, nas Américas, na Ásia. 


\subsection{Geo-helmintos no Brasil}

A Organização Mundial de Saúde (OMS, 2013) relatou que, nas últimas décadas, ocorreram importantes melhorias nas condições de vida e saúde da população no Brasil, resultantes de mudanças nas políticas econômicas e sociais no país. Porém, contaminação do solo de praças e parques por geohelmintos está presente em todas as regiões. Os dados apresentados a seguir (Tabela 1) foram levantados de acordo com trabalhos publicados entre os anos 1976 e 2018, em estudos com amostras de solo e fezes presentes no solo em praças e parques.

\subsection{Geo-helmintos no local de estudo}

No município de Botucatu, Santarém et al. (1998) realizaram um estudo em dez parques e praças públicas, contendo caixas de areia ou playgrounds, para a coleta de amostras de solo, destas praças e parques submetidos ao estudo, seis apresentaram contaminação por ovos de Toxocara spp.

No entanto, apesar da importância deste estudo, não foram realizados estudos nos últimos vinte anos de contaminação do solo por geo-helmintos neste município, que teve um crescimento populacional de 105.533 habitantes para 144.820 habitantes, representando um crescimento de 37,22\% (IBGE, 2018). 
Tabela 1- Presença de ovos e/ou larvas de geo-helmintos em amostras de solo e/ou fezes no solo nas diferentes unidades federativas (UF) do Brasil, no período de 1976 a 2018.

\begin{tabular}{|c|c|c|c|c|c|}
\hline Região & UF & Cidade & $\begin{array}{l}\text { Tipo de } \\
\text { Amostra }\end{array}$ & Resultados & Referências \\
\hline \multirow[t]{6}{*}{ SUL } & PR & Londrina & Terra & $\begin{array}{l}\text { Toxocara spp. } \\
\text { (ovos) })^{1,2}\end{array}$ & $\begin{array}{r}\text { CHIEFFI e } \\
\text { MULLER, } 1976\end{array}$ \\
\hline & PR & Maringá & Areia & $\begin{array}{l}\text { Toxocara spp. } \\
\text { (ovos) }^{34} \\
\text { Ancylostomatoidea } \\
\text { (ovos e/ou } \\
\text { larvas), } \\
\text { Hymenolepis } \\
\text { diminuta (ovos) } \\
\text { Ascaris spp. } \\
\text { (ovos) }^{3,4} \\
\text { Taeniidae (ovos) }\end{array}$ & TIYO et al., 2008 \\
\hline & PR & Curitiba & terra/areia & $\begin{array}{l}\text { Strongyloides spp. } \\
\text { (larvas) }^{5} \\
\text { Ancylostoma spp. } \\
\text { (ovos) }^{3,5} \\
\text { Toxocara spp. } \\
\text { (ovos) }^{3} \\
\text { Strongyloidea } \\
\text { (ovos) }^{5} \\
\text { Trichuris spp. } \\
\text { (ovos) }^{3}\end{array}$ & $\begin{array}{r}\text { SPRENGER et al., } \\
2014\end{array}$ \\
\hline & $\mathrm{RS}$ & $\begin{array}{l}\text { Balneário } \\
\text { Cassino }\end{array}$ & fezes & $\begin{array}{l}\text { Ancylostoma spp. } \\
\text { (ovos/ larvas) }^{6} \\
\text { Trichuris spp. } \\
\text { (ovos) }^{6} \\
\text { Toxocara spp. }_{\text {(ovos) }^{6}}\end{array}$ & $\begin{array}{r}\text { SCAINI et al., } \\
2003\end{array}$ \\
\hline & $\mathrm{RS}$ & Pelotas & & $\begin{array}{l}\text { Ancylostomatoidea } \\
\text { (ovos) }^{8} \\
\text { Toxocara spp. } \\
\text { (ovos) }^{8} \\
\text { Trichuris spp. } \\
\text { (ovos) }^{8} \\
\text { Ascaris spp. } \\
\text { (ovos) }^{8} \\
\text { Capillaria spp. }_{\text {(ovos) }^{8}}\end{array}$ & $\begin{array}{r}\text { MOURA et al., } \\
2013\end{array}$ \\
\hline & $\mathrm{RS}$ & $\begin{array}{l}\text { Capão do } \\
\text { Leão, } \\
\text { Pelotas, } \\
\text { Pinheiro } \\
\text { Machado e } \\
\text { Santana do } \\
\text { Livramento }\end{array}$ & fezes & $\begin{array}{l}\text { Ancylostoma spp. } \\
\text { (ovos) } \\
\text { Toxocara spp. } \\
\text { (ovos) }^{6}\end{array}$ & $\begin{array}{r}\text { LOPES et al., } \\
2014\end{array}$ \\
\hline
\end{tabular}




\begin{tabular}{|c|c|c|c|c|c|}
\hline & $\mathrm{RS}$ & Caxias do Sul & Terra & $\begin{array}{l}\text { Ancylostoma spp. } \\
\text { (ovos) } \\
\text { Strongyloides spp. } \\
\text { (larvas) }^{3,4}\end{array}$ & $\begin{array}{r}\text { BORTOLATTO et } \\
\text { al., } 2017\end{array}$ \\
\hline & SC & Laguna & fezes & $\begin{array}{l}\text { Ancylostoma spp. } \\
\text { (ovos) }^{4} \\
\text { Toxocara spp. } \\
\text { (ovos) } \\
\text { Spirometra spp. } \\
\text { (ovos) }^{4} \\
\text { Trichuris spp. }_{\text {(ovos) }}^{4}\end{array}$ & $\begin{array}{r}\text { BLAZIUS et al., } \\
2006\end{array}$ \\
\hline \multirow[t]{8}{*}{ SUDESTE } & $\begin{array}{l}\text { SP } \\
\text { SP }\end{array}$ & $\begin{array}{l}\text { Botucatu } \\
\text { Praia Grande }\end{array}$ & $\begin{array}{l}\text { Areia } \\
\text { fezes }\end{array}$ & $\begin{array}{l}\text { Toxocara spp. } \\
\text { (ovos) }^{7} \\
\text { Ancylostoma spp. } \\
\text { (ovos e/ou larvas) }^{6} \\
\text { Toxocara spp. } \\
\text { (ovos) }^{6}\end{array}$ & $\begin{array}{r}\text { SANTARÉM et al., } \\
1998 \\
\text { CASTRO et al., } \\
2005\end{array}$ \\
\hline & SP & Araçatuba & Areia & $\begin{array}{l}\text { Ancylostoma spp. } \\
\text { (ovos e/ou larvas) }^{8}\end{array}$ & $\begin{array}{r}\text { NUNES et al., } \\
2000\end{array}$ \\
\hline & $\mathrm{SP}$ & São Paulo & Terra & $\begin{array}{l}\text { Toxocara spp. } \\
\text { (ovos) })^{1}\end{array}$ & $\begin{array}{r}\text { QUEIROZ et al., } \\
2006\end{array}$ \\
\hline & SP & $\begin{array}{l}\text { Ribeirão } \\
\text { Preto }\end{array}$ & fezes & $\begin{array}{l}\text { Ancylostoma spp. } \\
\text { (ovos) } \\
\text { Toxocara spp. } \\
\text { (ovos) }\end{array}$ & $\begin{array}{r}\text { CAPUANO e } \\
\text { ROCHA, } 2006\end{array}$ \\
\hline & $\mathrm{SP}$ & Fernandópolis & Terra & $\begin{array}{l}\text { Toxocara spp. } \\
\text { (ovos) } \\
\text { Trichuris spp. } \\
\text { (ovos) } \text { ( }^{1,5,6} \\
\text { Ancylostomatoidea } \\
\text { (ovos) }^{1,5,6}\end{array}$ & $\begin{array}{r}\text { CASSENOTE et } \\
\text { al., } 2010\end{array}$ \\
\hline & $\mathrm{SP}$ & $\begin{array}{l}\text { Presidente } \\
\text { Prudente }\end{array}$ & Terra & Toxocara spp.² & $\begin{array}{r}\text { SANTARÉM et al., } \\
2012\end{array}$ \\
\hline & $\mathrm{SP}$ & Santos & Areia & $\begin{array}{l}\text { Ancylostoma } \\
\text { (ovos/ larvas) }^{2,4,5} \\
\text { Toxocara (ovos) } \\
2,4,5 \\
\text { Ascaris (ovos) } \\
\text { Trichostrongylus }^{2,4,5} \\
\text { (ovos) }^{2,4,5} \\
\text { Strongyloides } \\
\text { (larvas) }^{2,4,5}\end{array}$ & $\begin{array}{r}\text { ROCHA et al., } \\
2011\end{array}$ \\
\hline & ES & $\begin{array}{l}\text { Castelo e } \\
\text { Cachoeiro de } \\
\text { Itapemirim }\end{array}$ & Areia & $\begin{array}{l}\text { Ancylostomatoidea } \\
\text { (ovos/ larvas) }^{9} \\
\text { Ascaridoidea } \\
\text { (ovos) } \\
\text { Trichuroidea }^{9} \\
\text { (ovos) }^{9}\end{array}$ & $\begin{array}{r}\text { MARTINS e } \\
\text { ALVES, } 2018\end{array}$ \\
\hline
\end{tabular}


MG Lavras

MG Uberlândia

MT Cuiabá

RJ Valença

MS Campo

Grande terra

/areia

OESTE

NORDESTE BA Itabuna

fezes

Terra

fezes

fezes
Ancylostoma spp. (larvas) $^{9}$

GUIMARÃES et

al.,2005

Ancylostoma spp.

(ovos/ larvas) $^{4}$

Ascaridoidea

(ovos) $)^{4,1}$

Trichuris spp.

(ovos) $^{4,10}$

Strongyloides spp.

(larvas) $^{4,10}$

Ancylostoma spp. (ovos) $^{9}$

CIRNE et al., 2017

Toxocara spp.

(ovos)

ARAÚJO et al.,

Ancylostoma spp.

1999

(ovos) $^{9}$

Ancylostoma spp.

(ovos) ${ }^{4,6}$

SOUSA, et al.,

Trichuris spp.

2007

(ovos) $)^{4,6}$

Toxocara spp.

(ovos) $)^{4,6}$

Platynossomum

spp. (ovos) $)^{4,6}$

Ancylostoma spp.

(ovos/ larvas) ${ }^{4}$

CAMPOS FILHO

Strongyloides spp.

et al., 2008

(larvas) ${ }^{4}$

Toxocara spp.

$\left(\right.$ ovos) ${ }^{4}$

Trichuris spp.

(ovos) ${ }^{4}$

BA Salvador Areia

$$
\begin{aligned}
& \text { Ancylostoma spp. } \\
& \text { (ovos/ larvas) }^{3} \\
& \text { Toxocara spp. } \\
& \text { (ovos) } \\
& \text { Trichuris spp. }^{3} \\
& \text { (ovos) }^{3}
\end{aligned}
$$

SANTOS et al., 2006

Areia

Toxocara spp. (ovos) $)^{3,6}$

FERREIRA et al., Ancylostoma spp. 2018

$$
\text { (ovos) })^{3,6}
$$

Técnicas laboratoriais: 1-Flutuação com dicromato de sódio; 2- Flutuação com sulfato de zinco; 3- Centrífugoflutuação com sulfato de zinco; 4- Sedimentação; 5- Técnica de Baermann; 6- Flutuação simples com cloreto de sódio; 7- Centrífugo-flutuação com hidróxido de sódio; 8- Centrífugo-flutuação com dicromato de sódio; 9- Centrífugoflutuação com sacarose; 10 - Sedimentação com éter 


\subsection{Principais geohelmintíases}

Entre as geohemintíases, a larva migrans visceral, juntamente com a larva migrans cutânea, são as principais patologias causadas por espécies geo-helminticas zoonóticas. Os hábitos de higiene pessoal precárias, bem como o consumo de vegetais crus cultivados em hortas contaminadas podem resultar em infecções crônicas por esses geo-helmintos (MAGNAVAL et al., 2001).

A larva migrans visceral (LMV) é uma zoonose ocasionada pela ingestão de ovos contendo larvas infectantes do gênero Toxocara, especialmente o $T$. canis, cujo hospedeiro definitivo é o cão. $O T$. cati, cujo hospedeiro é o gato, pode estar envolvido secundariamente na toxocaríase humana (SANTARÉM et al., 2009). Apesar disso, a doença tem sido negligenciada como problema de saúde pública (ALTCHEH et al., 2003) e sua prevalência em humanos subestimada (ALDERETE et al., 2003). Além disso, os hábitos culturais de alimentar-se de carne e/ou vísceras cruas ou mal cozidas podem aumentar a possibilidade de infecção de larvas de Toxocara presentes em tecidos de hospedeiros paratênicos, tais como frangos (NAKAGURA et al., 1989), cordeiros (SALEM e SCHANTZ, 1992) ou coelhos (STURCHLER et al., 1990) constituindo em um potencial risco de infecção.

A apresentação clínica da infecção por Toxocara spp. em seres humanos foi classificada sistematicamente em quatro grupos: larva migrans visceral clássica (LMV), larva migrans visceral oculta (LMVO), larva migrans ocular (LMO) e a larva migrans neurológica (MAGNAVAL et al., 2001; OVERGAAW, 2013; KUENZLI et al., 2016; MACHADO e ARAUJO, 2017).

\subsubsection{Larva Migrans Visceral Clássica (LMV)}

A forma clássica da toxocaríase foi primeiramente descrita por Beaver (1952) como Síndrome da Larva Migrans Visceral. É uma doença que acomete principalmente crianças entre dois e sete anos de idade. A gravidade e o alcance dos sinais clínicos da LMV dependem do tecido invadido, o número de larvas migratórias e a idade do hospedeiro. A LMV é descrita como uma patologia sistêmica grave, caracterizada por eosinofilia, hepato- 
esplenomegalia, febre, hipergamaglobulinemia com leucocitose (DESPOMMIER, 2003).

\subsubsection{Larva Migrans Visceral Oculta (LMVO)}

Por definição, a LMVO caracteriza-se por sinais clínicos inespecíficos, não associados à forma clássica. A expressão clínica da toxocaríase oculta pode variar desde o envolvimento pulmonar como asma, bronquite aguda, pneumonite com ou sem acúmulo de eosinófilos no pulmão (Síndrome de Loeffler) a alterações dermatológicas, tais como urticária crônica ou eczema, linfadenopatia, miosite e síndrome pseudoreumática (LE LUYER et al., 1990; WOLFROM et al.,1995). A toxocaríase oculta pode ser confirmada pelo alívio ou desaparecimento dos sinais após tratamento (PAWLOWSKI, 2001).

\subsubsection{Larva Migrans Ocular (LMO)}

A patogênese da LMO ocorre pela penetração da larva no globo ocular através dos vasos retinianos, e o bloqueio dos vasos da região ou da periferia da retina, promovendo uma formação granulomatosa. Os sinais clínicos mais comuns são o estrabismo, diminuição unilateral da visão, inflamação vítrea e leucocoria (EL MATRI et al.,1990). A LMO também pode causar endoftalmite difusa ou papilite. Pode ocorrer a formação de uma membrana neovascular coroide, com posterior coriorretinite (DESPOMMIER, 2003).

A baixa sensibilidade dos testes sorológicos para LMO está provavelmente relacionada à baixa carga parasitária ou ao longo período entre o início da infecção e o teste sorodiagnóstico. O período entre o início da doença e a positividade sorológica foi de menos de seis meses no caso de LMV, enquanto que na LMO foi de aproximadamente dois anos (SCHANTZ, 1989).

\subsubsection{Larva Migrans neurológica (LMN)}

A migração das larvas sistema nervoso central é rara. Na LMN, a lesão tecidual é induzida pela reação inflamatória ao parasita, não pela migração em si. A LMN surge da invasão larvas L3 de Toxocara spp. no cérebro e medula espinhal, causando meningite, encefalite, mielite, vasculite cerebral e 
convulsões. A apresentação clínica consiste em um amplo espectro de manifestações neurológicas, embora normalmente seja assintomática (MAGNAVAL e GLICKMAN, 2006).

O diagnóstico de LMN é baseado na elevação do anticorpos presentes no líquido cefalorraquidiano ou no soro, eosinofilia no sangue ou líquido cefalorraquidiano e melhora clínica após terapia antihelmíntica. $\mathrm{Na}$ ressonância magnética $(\mathrm{RM})$ apresenta um ou vários pontos de lesões subcorticais, corticais ou de substância branca. Esses achados de imagem são sugestivos, mas não específicos da neurotoxocaríase. $O$ diagnóstico definitivo é feito por confirmação histológica (SANCHES et al., 2018).

\subsubsection{Larva Migrans Cutânea}

A larva migrans cutânea (LMC) é causada pela penetração de larvas infectantes (L3) de ancilostomídeos de cães e gatos no ser humano. As crianças são consideradas o grupo de risco, pois são mais expostas ao terem acesso com solo de locais que podem estar contaminados, como praias e caixas de areia de parques de recreação (ACHA e SZYFRES, 2003).

O A. braziliense é o principal agente etiológico da LMC ou dermatite serpiginosa ou 'bicho geográfico" no ser humano, causada pela migração da larva no estágio L3 pelo tecido subcutâneo, provocando erupções e geralmente acompanhadas de intenso prurido (TAYLOR et al., 2010; ANDERSON, 2000).

A infecção ocorre após contato com solo contaminado com as fezes de cães e gatos. Como o ser humano não é o hospedeiro definitivo, as larvas não conseguem atingir a fase adulta e continuam migrando sob a pele durante várias semanas causando prurido intenso e erupções (HEUKELBACH et al., 2004).

A enfermidade tem sido registrada em diversos países, principalmente naqueles de clima subtropical e tropical. No Brasil, é uma doença frequentemente encontrada na região litorânea, embora tenham sido observados casos em cidades do interior (ARAUJO et al., 1999). 


\subsection{Métodos laboratoriais de diagnóstico de geo-helmintos}

O diagnóstico de geo-helmintos pode ser feito pela pesquisa de ovos ou larvas e, eventualmente pelo parasito adulto, nas amostras fecais, por meio de exames de flutuação ou sedimentação. Diversos fatores estão associados com a visualização de ovos nas fezes, entre eles, a homogeneização das fezes, a intensidade da carga parasitária e a variação diária do número de ovos eliminados, sendo esta eliminação, por vezes, intermitente (ARAÚJO et al., 2003).

A textura do solo (terra ou areia) e soluções de flutuação $(\mathrm{NaCl}$ saturado, sacarose, $\mathrm{NaNO}_{3}$ e $\mathrm{ZnSO}_{4}$ ) podem influenciar na recuperação de ovos de geo-helminto comos os de Toxocara spp. apresentando interações significativas entre os tipos de solo e as soluções de flotação ( $\mathrm{LOH}$ e ISRAF,1998).

Os métodos de concentração por flutuação (gravitacional ou por centrifugação) se baseiam na diferença de densidade específica (DE) entre as estruturas parasitárias (ovos, cistos ou oocistos), os detritos fecais e a solução empregada para flutuação. As soluções mais usadas para flutuação incluem as soluções de: cloreto de sódio, açúcar (solução de Sheather), nitrato de sódio, sulfato de magnésio, sulfato de zinco (DRYDEN et al., 2005).

Como a densidade específica da maioria das formas evolutivas dos parasitas varia 1,05 a 1,23, o emprego de soluções com alta densidade específica permite a separação de cistos e oocistos de protozoários e de ovos e larvas de helmintos, fazendo com que possam ser recuperados na superfície, enquanto os detritos permanecem no fundo do tubo. Dessa forma, o material examinado em microscópio é uma preparação mais limpa do que a obtida pela concentração por sedimentação (DADA e LINDQUIST, 1982).

As preparações obtidas nos métodos de flutuação devem ser examinadas imediatamente, pois as soluções empregadas produzem distorções nas estruturas parasitárias dificultando a sua identificação (DRYDEN et al., 2005). 
A sedimentação pode ser obtida de forma natural (gravitacional), por centrifugação ou por meios químicos. Uma das vantagens do método é a simplicidade e o fato de não alterar a viabilidade dos ovos. As desvantagens incluem o longo tempo requerido para a sedimentação espontânea e o fato de produzir uma preparação com grande quantidade de detritos. A sedimentação por centrifugação elimina este inconveniente. A filtração prévia das amostras e/ ou a adição de formol-éter ou de acetato de etila às amostras facilitam o exame microscópio do sedimento, pois produzem uma preparação mais limpa (TRUANT et al.,1981).

O Método de Baermann-Moraes é o método que detecta larvas de nematódeos vivas, por hidrotropismo e termotropismo positivo. É utilizado para detectar larvas de Strongyloides stercoralis e também larvas de ancilostomídeos. Para diferenciar as larvas pode-se utilizar coloração pelo lugol. Quando coradas, é possível observar que as larvas de Strongyloides spp. possuem vestíbulo bucal curto na região anterior e primórdio genital na região posterior do corpo do parasito. Por outro lado, as larvas de ancilostomídeos que vestíbulo bucal comprido e sem primórdio genital visível (MORAES, 1948; RUGAl et al, 1954). 


\section{OBJETIVOS}

\subsection{Objetivo geral}

Identificar os principais gêneros de geo-helmintos e sua ocorrência no munícipio de Botucatu, SP.

\subsection{Objetivos específicos}

Avaliar a prevalência de geo-helmintos no solo de praças no município de Botucatu, SP.

Avaliação dos fatores de risco que colaboram para a contaminação do solo nas praças de Botucatu, SP . 


\section{REFÊRENCIAS BIBLIOGRÁFICAS ${ }^{1}$}

ACHA, P. N., SZYFRES, B. Zoonosis y enfermidades transmisibles comunes al hombre ya los animales. Pan American Health Organization. 3 ed., v.3, p.321324., 2003.

ALDERETE, J.M.S., JACOB, C.M.A., PASTORINO, A.C., ELEFANT, G.R., CASTRO, A.P.M., FOMIN, A.B.F., CHIEFFI, P.P. Prevalence of Toxocara infection in schoolchildren from the Butantã region, São Paulo, Brazil. Memórias do Insituto Oswaldo Cruz, v.98, p.593-597, 2003.

ALTCHEH, J., NALLAR, M., CONCA, M., BIANCARDI, M., FREILIJ, H. Toxocariasis: aspectos clínicos y de laboratorio em 54 pacientes. Anais de Pediatria, v.58, p.425-431, 2003.

ANDERSON, R. C. Nematode parasites of vertebrates: Their development and transmission. $2^{\text {nd }}$ ed., Oxford: CABI Publishing. 2000.

ARAÚJO, F. R. D., CROCCI, A. J., RODRIGUES, R. G. C., AVALHAES, J. D. S., MIYOSHI, M. I., SALGADO, F. P., PEREIRA, M. L. Contaminação de praças públicas de Campo Grande, Mato Grosso do Sul, Brasil, por ovos de Toxocara e Ancylostoma em fezes de cães. Revista da Sociedade Brasileira de Medicina Tropical, p. 581-583, 1999.

ARAÚJO A.J.U.S., KANAMURA H.Y.,DIAS L.C.S, GOMES J.F., ARAÚJO S.M. Coprotest $\AA^{\circledR}$ quantitativo: quantificação de ovos de helmintos em amostras fecais utilizando-se sistema de diagnóstico comercial. Jornal Brasileiro de Patologia e Medicina Laboratorial, v. 39, n. 2, p. 115-124, 2003.

BEAVER P., SNYDER C.H., CARRERA G.M., DENT J.H., LAFFERTY J.W. Chronic eosinophilia due to visceral larva migrans: report of three cases. Pediatrics. 9:7-19, 1952.

BLASZKOWSKA, J., KURNATOWSKI, P., DAMIECKA, P. Contamination of the soil by eggs of geohelminths in rural areas of Lodz district (Poland). Helminthologia, v. 48, n. 2, p. 67-76, 2011.

BLAZIUS, R. D., SILVA, O. S., KAULING, A. L., RODRIGUES, D. F. P., LIMA, M. C. Contaminação da areia do Balneário de Laguna, SC, por Ancylostoma spp, e Toxocara spp em amostras fecais de cães e gatos. Arquivos Catarinenses de Medicina, v. 35, n. 3, p. 55-58, 2006.

1-ASSOCIAÇÃO BRASILEIRA DE NORMAS TÉCNICAS. NBR6023: informação e documentação, referência elaboração. Rio de Janeiro, 2002. 
BOJAR, H., KLAPEC, T. Contamination of soil with eggs of geohelminths in recreational areas in the Lublin region of Poland. Annals of Agricultural and Environmental Medicine, v. 19, n. 2, 2012.

BORTOLATTO, J. M., SNIEGOVSKI, M. M., BERNARDI, S. T., CRIPPA, L. B., RODRIGUES, A. D. Prevalence of parasites with zoonotic potential in soil from the main public parks and squares in Caxias do Sul, RS, Brazil. Revista de Patologia Tropical/Journal of Tropical Pathology, v. 46, n. 1, p. 85-93, 2017.

BRADBURY, R., TRAUB, R. J. Hookworm Infection in Oceania._In: Neglected Tropical Diseases-Oceania. Springer International Publishing, p. 33-68, 2016.

CAMPOS FILHO, P. C.,BARROS, L. M., CAMPOS, J. O., BRAGA, V. B., CAZORLA, I. M., ALBUQUERQUE, G. R., CARVALHO, S. M. Parasitas zoonóticos em fezes de cães em praças públicas do município de Itabuna, Bahia, Brasil. Revista Brasileira de Parasitologia Veterinária, v. 17, n. 4, p. 206209, 2008.

CAPUANO, D. M., ROCHA, G. M. Contaminação ambiental por ovos de Toxocara sp. no município de Ribeirão Preto, Estado de São Paulo, Brasil. Revista do Instituto de Medicina Tropical de São Paulo, v. 47, p. 223226, 2005.

CAssenote, A. J. F., PINTO Neto, J. M., LiMA-CATELANI, A. R. D. A., FERREIRA, A. W. . Contaminação do solo por ovos de geo-helmintos com potencial zoonótico na municipalidade de Fernandópolis, Estado de São Paulo, entre 2007 e 2008. Revista Sociedade Brasileira de Medicina Tropical, v. 44, p.371-374, 2011.

CASTRO, J.M., SANTOS, S. V., MONTEIRO, N. A. Contaminação de canteiros da orla marítima do Município de Praia Grande, São Paulo, por ovos de Ancylostoma e Toxocara em fezes de cães. Revista Sociedade Brasileira de Medicina Tropical, v. 38, n. 2, p.199-201, 2005.

CDC-CENTER FOR DISEASE CONTROL AND PREVENTION. Guidelines for veterinarians:prevention of zoonotic transmission of ascarids and hookworms of dogs and cats.

Disponível em: http://www.cdc.gov/ncidod/dpd/parasites/ascaris/prevention.pdf Acesso em: 15 junho 2018.

CHIEFFI, P. P., MÜLLER, E. E. Prevalência de parasitismo por Toxocara canis em cães e presença de ovos de Toxocara sp. no solo de localidades públicas da zona urbana do município de Londrina, Estado do Paraná, Brasil. Revista de Saúde Pública, v. 10, n. 4, p. 367-372, 1976.

CHIEFFI, P.P., AMATO NETO, V. Vermes, verminoses e a saúde pública. Revista Ciência e Cultura, Campinas, v. 55, p. 41-43p, 2003. 
CHIEFFI, P.P. Helmintoses e alterações ambientais e climáticas/Helminthiasis and environmental and climatic changes. Arquivos Médicos dos Hospitais e da Faculdade de Ciências Médicas da Santa Casa de São Paulo, v. 60, n. 1, p. $27-$ 31, 2015.

CIRNE, F. S.L., DA SILVA, T., CARVALHO, A. C. F., DIAS, P. M., RAMOS, C. D.,BATISTA, L. C. D. S. O. Contaminação ambiental por ovos de Ancylostoma spp. e Toxocara spp. Em áreas de seis praças públicas do município de valença, estado do rio de janeiro. Acta Biomedica Brasiliensia, v. 8, n. 1, p. 3542, 2017.

CROMPTON, D.W. Ascaris and ascariasis. Advances in Parasitology, v.48, p 285-375, 2001.

CUNHA, A. R., MARTINS, D. Classificação climática para os municípios de Botucatu e São Manuel, SP. Revista Irriga, p. 1-11, 2009.

DADA B.J.O., LINDQUIST W.D. Prevalence of Toxocara spp eggs in some public grounds and highway rest areas in Kansas. Journal of Helmintology 53:145- 146, 1979.

DESPOMMIER, D. Toxocariasis: clinical aspects, epidemiology, medical ecology, and molecular aspects. Clinical Microbiology Reviews, v. 16, n. 2, p. 265-272, 2003.

DRYDEN, M. W., PAYNE, P. A., RIDLEY, R., SMITH, V. Comparison of common fecal flotation techniques for the recovery of parasite eggs and oocysts. Veterinary Therapy, v. 6, n. 1, p. 15-28, 2005.

EL MATRI, L., GHORBAL, M., AYADI, A., BEN NACEUR, B.,TRIKI, MF. Localisation oculaire à Toxocara canis apparemment bilaterale. Journal Français d'Ophtalmologie, v.13, p. 303-308, 1990

FAUST, E.C., D'ANTONI, J.S., ODOM, V., MILLER, M. J., PERES, C., SAWITZ.W., THOMEN L. F., TOBIE, J., WALKER, H. A critical study of clinical laboratory technics for the diagnosis of protozoan cysts and helminth eggs in feces I. Preliminary communication. American Journal of Tropical Medicine, v.18, p.169-183, 1938.

FERREIRA, I. S., JUNIOR, M. N., MORAES, M. S., MAGGI, L., BRILHANTE, A. F., SABINO, K. C. Frequência de Geo-Helmintos em áreas recreativas da cidade de Rio Branco, estado do Acre, Brasil. South American Journal of Basic Education, Technical and Technological, v. 5, n. 1, 2018.

FONSECA, E. O. L., TEIXEIRA, M. D. G., BARRETO, M. L., CARMO, E. H., COSTA, M. D. C. N. Prevalência e fatores associados às geo-helmintíases em 
crianças residentes em municípios com baixo IDH no Norte e Nordeste brasileiros. Caderno Saúde Pública, Rio de Janeiro, 26(1):143-152, 2010.

GORDON, C., KURSCHEID, J., JONES, M., GRAY, D., MCMANUS, D. Soiltransmitted helminths in tropical Australia and Asia. Tropical medicine and infectious disease, v. 2, n. 4, p. 56, 2017.

GUIMARÃES, A. M., ALVES, E. G. L.,REZENDE, G. F. Ovos de Toxocara sp. e larvas de Ancylostoma sp. em praça pública de Lavras, MG. Revista Saúde Pública, v. 39, n. 2, p. 293- 295, 2005.

HEUKELBACH, J., WILCKE, T., FELDMEIER, H. Cutaneous larva migrans (creeping eruption) in an urban slum in Brazil. International Journal of Dermatology, v. 43, n. 7, p. 511-515, 2004.

HOSTE, H. Adaptive physiological processes in the host during gastrointestinal parasitism. International Journal for Parasitology, v. 31, n. 3, p. 231-244, 2001.

HOTEZ P.J., BUNDY D.A.P., BEEGLE K., et al., eds. Helminth infections: soiltransmitted helminth infections and Schistosomiasis. In: Disease control priorities in developing countries, $2^{\text {nd }}$ ed., World Bank Publications, 2006.

HOTEZ, P. J., KAMATH, A. Neglected tropical diseases in sub-Saharan Africa: review of their prevalence, distribution, and disease burden. PLoS neglected tropical diseases, v. 3, n. 8, p. e412, 2009.

IBGE - INSTITUTO BRASILEIRO DE GEOGRAFIA E ESTATÍSTICA. Censo demográfico.

Disponível

em

<https://cidades.ibge.gov.br/brasil/sp/botucatu/panorama>. Acesso em 22 de maio de 2019.

JALETA, T. G., ZHOU, S., BEMM, F. M., SCHÄR, F., KHIEU, V., MUTH, S., STREIT, A . Different but overlapping populations of Strongyloides stercoralis in dogs and humans-Dogs as a possible source for zoonotic strongyloidiasis. Journal PLoS Neglected Tropical Diseases, v. 11, n. 8, p. 5752, 2017.

JIA, T. W., MELVILLE, S., UTZINGER, J., KING, C. H., ZHOU, X. N. Soiltransmitted helminth reinfection after drug treatment: A Systematic Review and Meta - Analysis. PLoS Neglected Tropical Diseases, v.6, n.5, 1621, 2012.

KIRCHHEIMER, R., JACOBS, D.E., Toxocara species egg contamination of soil from children's play areas in southern England. Veterinary Record. 163, p. 394395, 2008.

KUENZLI, E., NEUMAYR, A., CHANEY, M., BLUM, J. Toxocariasis -associated cardiac diseases - A systematic review of the literature. Revista Acta Tropica, v. 154, p. $107-120,2016$. 
KÖPPEN, W., GEIGER, R. Klimate der Erde. Gotha: Verlag Justus Perthes. 1928.

LE LUYER, B., MENAGER, V., AUDEBeRT, C., LE ROUX, P., BRIQUET, M. T., BOULLOCHE, J. Inflammatory joint disease as a manifestation of Toxocara canis larva migrans. In: Annales de Pediatrie, p. 445-448, 1990.

LOH, A. G., ISRAF, D. A. Tests on the centrifugal flotation technique and its use in estimating the prevalence of Toxocara in soil samples from urban and suburban areas of Malaysia. Journal of helminthology, v. 72, n. 1, p. 39-42, 1998.

LOPES, T. V., FERNANDES, C. P. M., MICHELON, L., HIJANO, A., FÉLIX, S. R., DE VARGAS SCHONS, S., DE OLIVEIRA NOBRE, M. Parasitas zoonóticos em fezes de cães de praças públicas em municípios da região sul do Rio Grande do Sul, Brasil. Revista Brasileira de Higiene e Sanidade Animal, v. 8, n. 2, p. 242-250, 2014.

MACHADO, E. R., ARAUJO, L. B. Human Toxocariasis: Secondary Data Analysis. Annals of Clinical Cytology and Pathology, v. 3, n. 6, p. 1075, 2017

MAGNAVAL, J. F., GLICKMAN, L. T., DORCHIES, P., MORASSIN, B. Highlights of human toxocariasis. The Korean Journal of Parasitology, v. 39, n. 1, p. 1, 2001.

MAGNAVAL, J.F., GLICKMAN, L.T. Management and treatment options for human toxocariasis. Toxocara: the enigmatic parasite, p. 113-126, 2006.

MARQUES, J. P., GUIMARÃES, C. D. R., BOAS, A. V., CARNAÚBA, P. U., MORAES, J. D. Contamination of public parks and squares from Guarulhos (São Paulo State, Brazil) by Toxocara spp. and Ancylostoma spp. Revista do Instituto de Medicina Tropical de São Paulo, v. 54, n. 5, p. 267-271, 2012.

MARTINS, R.S., ALVES, V.M.T. Análise de areia de parques públicos nos municípios de Castelo e Cachoeiro de Itapemirim. PUBVET, v. 12, p. 172, 2018.

McCARTHY, J., MOORE, T. A. Emerging helminthes zoonoses. International Journal of Parasitology, v.30, n.12-13, p.1351-1360, 2000.

MORAES, R. G. Contribuição para o estudo do Strongyloides stercoralis e da estrongiloidíase no Brasil. Revista do Serviço Especial de Saúde Pública, v. 1, p. 507-624, 1948.

MOURA, M. Q. D., JESKE, S., VIEIRA, J. N., CORRÊA, T. G., BERNE, M. E. A.,VILLELA, M. M. Frequency of geohelminths in public squares in Pelotas, RS, Brazil. Revista Brasileira de Parasitologia Veterinária, v. 22, n. 1, p. 175-178, 2013. 
MOTA, K.C.P., GRAMA, D.F., FAVA, N. M. N., ÚNGARI, L.P., FARIA, E.S.M., CURY, M.C. Revista do Instituto de Medicina Tropical de São Paulo, v. 60, 2018.

NAGAKURA, K., TACHIBANA, H., KANEDA, Y., KATO, Y. Toxocariasis possibly caused by ingesting raw chicken. Journal of Infective Diseases, 160, 735-73, 1989.

OJHA, S. C., JAIDE, C., JINAWATH, N., ROTJANAPAN, P., BARAL, P. The Journal of Infection in Developing Countries, v. 8, n. 01,p. 005-016, 2014

OLIVEIRA-ARBEX, A. P., DAVID, E. B., OLIVEIRA-SEQUEIRA., T. C. G., KATAGIRI, S., CORADI, S. T., GUIMARÃES, S. Molecular identification of Ancylostoma species from dogs and an assessment of zoonotic risk in lowincome households, São Paulo State, Brazil. Journal of Helminthology, v. 91, n. 1, p. 14-19, 2017.

ORGANIZACIÓN MUNDIAL DE LA SALUD. Salud em las Américas. Brasil. Disponível em: http://iris.paho.org/xmlui/handle/123456789/49307. Acesso em: 05 de dezembro 2018

OTERO, D., ALHO, A.M., NIJSSE, R., ROELFSEMA, J., OVERGAAUW, P., DE CARVALHO, L.M., 2018. Environmental contamination with Toxocara spp. eggs in public parks and playground sandpits of Greater Lisbon, Portugal. Journal of Infection and Public Health , v. 11, n. 1, p. 94-98, 2018.

OVERGAAUW, P.A.M., VAN KNAPEN, F.. Veterinary and public health aspects of Toxocara spp. Veterinary Parasitology, v. 193, n. 4, p. 398-403, 2013.

PAWLOWSKI, Z. Toxocariasis in humans: clinical expression and treatment dilemma. Journal of helminthology, v. 75, n. 4, p. 299-305, 2001.

PRESTES., L. F., AMBROZIO, C. L., ANTUNES, L. O., NAGEL, A. S., VILLELA, M. M. Análise parasitológica de cães recolhidos em canil Municipal de Pelotas, Río Grande do Sul, Brasil. The Biologist, v. 10, n. 2, p. 7, 2012.

QUEIROZ, M. L. D., SIMONSEN, M., PASCHOALOTTI, M.A., CHIEFFI, P. $P$. Frequency of soil contamination by Toxocara canis eggs in the south region of São Paulo municipality (SP, Brazil) in a 18 month period. Revista do Instituto de Medicina Tropical de São Paulo, v. 48, n. 6, p. 317-319, 2006.

ROCHA, S., PINTO, R. M. F., FLORIANO, A. P., TEIXEIRA, L. H., BASSILI, B., MARTINEZ, A., CASEIRO, M. M. Environmental analyses of the parasitic profile found in the sandy soil from the Santos municipality beaches, SP, Brazil. Revista do Instituto de Medicina Tropical de São Paulo, v. 53, n. 5, p. 277-281, 2011. 
ROLIM, G. S., CAMARGO, M. B. P. , LANIA, D. G., MORAES, J. F. L. Classificação climática de Köppen e de Thornthwaite e sua aplicabilidade na determinação de zonas agroclimáticas para o Estado de São Paulo. Bragantia, v.66, 711-720, 2007p.

RUGAI, E., MATTOS, T., BRISOLA, A. P. Nova técnica para isolar larvas de mematóides das fezes-Modificação do Método de Baermann. Revista do Instituto Adolfo Lutz, v. 14, n. 1, p. 5-8, 1954.

SALEM, G., SCHANTZ, P. Toxocaral visceral larva migrans after ingestion of raw lamb liver. Clinical infectious diseases, v. 15, n. 4, p. 743-744, 1992.

SÁNCHEZ, S.S., GARCÍA, .H. H., NICOLETTI, A. Clinical and magnetic resonance imaging findings of neurotoxocariasis. Frontiers in Neurology, v. 9, p. 53, 2018.

SANTARÉM, V.A., SARTOR, I. F., BERGAMO, MATSUBARA, F.M. Contaminação, por ovos de Toxocara spp, de parques e praças públicas de Botucatu, São Paulo, Brasil. Revista da Sociedade Brasileira de Medicina Tropical, p. 529-532, 1998.

SANTARÉM, V. A., RUBINSKY-ELEFANT, G.,CHESINE, P. A. F., LELI, F. N. C. Toxocaríase canina e humana. Revista Veterinária e Zootecnia, v. 16, n. 3, p. 437-447, 2009.

SANTARÉM, V.A., PEREIRA, V.C., ALEGRE, B.C.P. Revista Brasileira de Parasitologia Veterinária, v. 21, n. 3, p. 323-325, 2012.

SANTOS, N. M., DA SILVA, V. M. G., DOS SANTOS, A. B., DE SOUZA, T. P. Contaminação das praias por parasitos caninos de importância zoonótica na orla da parte alta da cidade de Salvador-BA. Revista de Ciências Médicas e Biológicas, v. 5, n. 1, 2006.

SCAINI, C. J., TOLEDO, R. N. D., LOVATEL, R. M., DIONELLO., M. A., GATTI, F. A. D. A., SUSIN, L. R. O., SIGNORINI, V. R. M. Contaminação ambiental por ovos e larvas de helmintos em fezes de cães na área central do Balneário Cassino, Rio Grande do Sul. Revista da Sociedade Brasileira de Medicina Tropical, v. 36(5): 617-619, set-out, 2003.

SCHANTZ, P.M. Toxocara larva migrans now. American Journal Tropical Medicine Hygiene, v.41, p.21-34, 1989.

SCHÄR, F., TROSTDORF, U., GIARDINA, F., KHIEU, V., MUTH, S., MARTI, H., ODERMATT, P. Strongyloides stercoralis: global distribution and risk factors. PLoS neglected tropical diseases, v. 7, n. 7, p. e2288, 2013. 
SOUSA, V. R. F., DALCIN, L., JUSTINO, C. H. S. Contaminação por fezes caninas das praças públicas de Cuiabá, Mato Grosso. Brazilian Journal of Veterinary Research and Animal Science, v. 44, n. 2, p. 132-136, 2007.

SPRENGER, L. K.,GREEN, K. T., MOLENTO, M. B. Geohelminth contamination of public areas and epidemiological risk factors in Curitiba, Brazil. Revista Brasileira de Parasitologia Veterinária, v. 23, n. 1, p. 69-73, 2014.

STÜRCHLER D., WEISS N., GASSNER M. Transmission of toxocariasis. Journal Infectious Diseases. p. 162-571, 1990.

TAYLOR, M. A., COOP, R. L., WALL, R. L. Parasitologia Veterinária. 3. ed. Rio de Janeiro: Guanabara Koogan, p. 870-881, 2017.

THAMSBORG, S. M., KETZIS, J., HORII, Y., MATTHEWS, J. B. Strongyloides spp. infections of veterinary importance. Parasitology, v. 144, n. 3, p. 274-284, 2017.

TIYO, R., GUEDES, T. A., FALAVIGNA, D. L. M., FALAVIGNA-GUILHERME, A. L. Seasonal contamination of public squares and lawns by parasites with zoonotic potential in southern Brazil. Journal of Helminthology, v. 82, n. 1, p. 16, 2008.

TRAVERSA, D., DI REGALBONO, A. F., DI CESARE, A., LA TORRE, F., DRAKE, J., PIETROBELLI, M. Environmental contamination by canine geohelminths. Parasites \& vectors, v. 7, n. 1, p. 67, 2014.

TRUANT, A. L., ELLIOTT, S. H., KELLY, M. T., SMITH, J. H. Comparison of formalin-ethyl ether sedimentation, formalin-ethyl acetate sedimentation, and zinc sulfate flotation techniques for detection of intestinal parasites. Journal of Clinical Microbiology, v. 13, n. 5, p. 882-884, 1981.

ULUKANLIGIL, M., SEYREK, A., ASLAN, G., OZBILGE, H., ATAY, S. Environmental pollution with soil-transmitted helminths in Sanliurfa, Turkey. Memorias do Instituto Oswaldo Cruz, v. 96, n. 7, p. 903-909, 2001.

WEESE, J. S., FULFORD, M. Companion animal zoonoses. Oxford: WileyBlackwell, 2011.36-40 p.

WILLIS, H.H. A simple levitation method for the detection of hookworm ova. Medicine Journal Australia, 29: 375-376, 1921.

WHO- Word Health Organzation. Soil-transmitted helminth infections. Updated September 2017.

Disponível em http://www.who.int/mediacentre/factsheets/fs366/en Acesso 15 março 2018. 
WHO- Word Health Organzation. Soil-transmitted helminth infections. Updated February 2018. Disponivel em : https://www.who.int/en/news-room/factsheets/detail/soil-transmitted-helminth-infections. Acesso 20 janeiro 2019.

WOLFROM, E., CHÊNE, G., BOISSEAU, H., BEYLOT, C.,GÉNIAUX, M., TAÏEB, A. Chronic urticaria and Toxocara canis. The Lancet, v. 345, n. 8943, p. 196, 1995. 


\section{CAPÍTULO 2}

Artigo submetido para Revista Saúde Público (Normas de publicação - ANEXO I)

Normas da publicação no anexo 
Título: Contaminação ambiental por geo-helmintos em praças do município de Botucatu, São Paulo.

Autor: Gilson Avelino Providelo

Instituição: Universidade Estadual Paulista "Júlio de Mesquita Filho". Faculdade de Medicina Veterinária e Zootecnia, câmpus de Botucatu. Departamento de Clínica Veterinária. Botucatu, SP, Brasil.

Email: gilsonavelinoprovidelo@gmail.com

Fone: (14) 99112-6161

Correspondência:

Gilson Avelino Providelo

Rua Zorobabel Ferreira de Sá, 404, Jardim Peabiru.

CEP: 18604-691

Botucatu, SP

\section{Co-autores:}

Raphaela Moreira de Oliveira

Instituição: Universidade Estadual Paulista "Júlio de Mesquita Filho". Faculdade de Medicina Veterinária e Zootecnia, câmpus de Botucatu. Departamento de Clínica Veterinária. Botucatu, SP, Brasil.

Email: raphaelamoreira7@gmail.com

Fone: (14) 98171-3597

Vamilton Alvares Santarém

Instituição: Docente da Universidade do Oeste Paulista (UNOESTE). Departamento de Ciência Animal. Presidente Prudente, São Paulo, Brasil

Email: vamilton@unoeste.br

Fone: (18)3229-2077

Cassiano Victoria

Instituição: Docente da Universidade Estadual Paulista "Júlio de Mesquita Filho". Faculdade de Medicina Veterinária e Zootecnia, câmpus de Botucatu. Departamento de Higiene Veterinária e Saúde Pública. Botucatu, SP, Brasil.

Email: cassiano.victoria@unesp.br

Fone: (014) 3880-2099

José Carlos de Figueiredo Pantoja

Instituição: Docente da Universidade Estadual Paulista "Júlio de Mesquita Filho". Faculdade de Medicina Veterinária e Zootecnia, câmpus de Botucatu. Departamento de Higiene Veterinária e Saúde Pública. Botucatu, SP, Brasil.

Email: jose.pantoja@unesp.br

Fone: (014) 3880-2092

Elizabeth Moreira dos Santos Schmidt

Instituição: Docente da Universidade Estadual Paulista "Júlio de Mesquita Filho". Faculdade de Medicina Veterinária e Zootecnia, câmpus de Botucatu. Departamento de Clínica Veterinária. Botucatu, SP, Brasil.

Email: elizabeth.schmidt@unesp.br

Fone: (014) 3880-2052 
Título: Contaminação ambiental por geo-helmintos em praças do município de Botucatu, São Paulo.

Title: Environmental contamination by geohelminths in squares in the municipality of Botucatu, São Paulo.

Título resumido: Contaminação em Botucatu por geo-helmintos.

Summary title: Contamination in Botucatu by geohelminths.

\section{Resumo}

Introdução- As espécies geo-hemínticas têm grande relevância em saúde pública, devido à resistência das suas formas infectantes (ovos e larvas) no ambiente. As infecções por geo-helmintos apresentam capacidade relevante de causar morbidade, mas com baixa mortalidade em seres humanos A importância desses parasitas é frequentemente subestimada por médicos veterinários e o público em geral, embora o Toxocara spp. e Ancylostoma spp. sejam os geo-helmintos mais relevantes, em termos de distribuição geográfica e importância clínica. Objetivo- Desta forma, o objetivo deste trabalho foi investigar a contaminação do solo por geo-helmintos em praças do município de Botucatu-SP, identificando a prevalência dos principais gêneros e sua ocorrência em praças de diferentes áreas do município. Métodos- As praças foram catalogadas e distribuídas entre as regiões administrativas (norte, sul, leste, oeste e central). As coletas de amostras de solo foram realizadas em dois momentos: momento I (de outubro a dezembro de 2017) e momento II (de fevereiro a março de 2018). Foram coletadas amostras de solo e avaliadas por meio das técnicas de centrífugo-sedimentação, centrífugo-flutuação com sulfato de zinco, e o método de Baermann-Moraes na perquisa por ovos e larvas de geo-helmintos. Resultados- A partir das análises das amostras do solo, a ocorrência de ovos de Toxocara sp. foi observada em 17,7\% (6/34) e $23,3 \%(7 / 30)$, respectivamente, nos momentos I e II. A contaminação por ovos de ancilostomídeos, foram observados em 6,6\% (2/30) sendo encontrados somente nas coletas realizadas no momento II. Conclusões- Os resultados obtidos no presente estudo demonstraram que o risco de contaminação de seres humanos por ovos de Toxocara spp. existe, pois foi o geo-helminto mais prevalente e o principal fator de risco observado, relacionado à presença de ovos de Toxocara spp. nos locais investigados. Neste cenário, políticas de saúde pública são necessárias para evitar a contaminação da população humana que frequenta esses locais, combinando abordagens para prevenir a contaminação do solo e o controle das geohelmintíases na população.

Descritores: contaminação do solo; geo-helmintos; Toxocara spp; zoonose. 


\section{Abstract}

Introduction- Soil-transmitted helminths are relevant in public health, due to the resistance of their infective forms (eggs and larvae) in the environment. Geohelminthiasis present a relevant capacity to cause morbidity and disability but with low mortality. The importance of these parasites is often underestimated by veterinarians and the general public, although Toxocara spp. and Ancylostoma spp. are the most important geohelminths in terms of geographical distribution and clinical importance. Objective- This study aimed to investigate the soil contamination by geohelminths in squares in the municipality of Botucatu-SP, to indentify the prevalence of the main genera and their occurrence in squares of different areas of the municipality. Methods- The squares were cataloged and distributed among administrative regions (north, south, east, west, and central). In this study, soil samples were collected and evaluated by means of centrifugal-sedimentation techniques, zinc sulfate, centrifugal-flotation and the Baermann-Moraes method in the search for eggs and larvae of geohelmints. The Samples were collected out in two times points: I (from October to December 2017) and II (from February to March 2018). From the analyzes of the soil samples, the occurrence of Toxocara sp. was observed in $17.7 \%(6 / 34)$ and $23.3 \%(7 / 30)$, respectively at time points I and II. The contamination by Ancylostomatidae eggs was observed in 6.6\% (2/30), being found only in samples obtained at time point II. Conclusions-The results of the present study demonstrated that the risk of human contamination by Toxocara spp. exists because it was the most prevalent geohelminth and the main risk factor observed and related to the presence of Toxocara spp. eggs. Therefore, public health policies are necessary to avoid contamination of the human population that have access these areas, combining approaches to prevent soil contamination and to control geohelminthiases in the population.

Descriptors: Soil contamination; geohelminths; Toxocara spp.; zoonosis. 


\section{Introdução}

Os geo-helmintos são um grupo de parasitas que necessitam que parte do ciclo evolutivo ocorra no solo, que proporciona condições adequadas para o desenvolvimento dos ovos e/ou a manutenção da viabilidade das larvas até o contato com um novo hospedeiro ${ }^{1-2}$. As espécies geo-hemínticas têm grande relevância em saúde pública, devido à resistência das suas formas infectantes (ovos e larvas) no ambiente ${ }^{3}$.

Entre os diversos geo-helmintos, destacam-se os ascarídeos (Ascaris spp. e Toxocara spp.), ancilostomídeos (Ancylostoma spp.), tricurídeos (Trichuris spp.) e o Strongyloides stercoralis. São frequentemente encontrados co-infectando o mesmo indivíduo, especialmente crianças em países em desenvolvimento ${ }^{4}$.

A prevalência dos geo-helmintos e suas formas infectantes sofrem influência das condições ambientais, sejam elas naturais, como características do solo e clima de determinada região, ou por modificações introduzidas pela atividade humana. Entretanto, também envolve fatores socioeconômicos, principalmente nas populações que residem em regiões de condições precárias de saneamento. Ademais, o processo crescente de urbanização observado atualmente, com a formação de grandes aglomerados de pessoas nas periferias, favorece a contaminação e ambiental por esses parasitas ${ }^{5-6}$.

As infecções por geo-helmintos apresentam capacidade relevante de causar morbidade, mas com baixa mortalidade. Entre os sinais clínicos estão a desnutrição, anemia ferropriva, síndrome de má absorção, obstrução intestinal, disenteria crônica, prolapso retal, complicações respiratórias e baixo ganho de peso. Nos quadros crônicos as geohelmintíases apresentam-se como doenças insidiosas e debilitantes, especialmente crianças e indivíduos imunossuprimidos ${ }^{7-8}$.

Entre as geohemintíases, a larva migrans visceral, juntamente com a larva migrans cutânea, são as principais patologias causadas por espécies geohelmínticas zoonóticas. Os hábitos de higiene pessoal precária, bem como 
o consumo de vegetais crus cultivados em hortas contaminadas podem resultar em infecções crônicas por esses geo-helmintos ${ }^{9}$.

No município de Botucatu, Santarém et al. ${ }^{10}$ realizaram um estudo em dez parques e praças públicas, contendo caixas de areia ou playgrounds, para a coleta de amostras de solo. No total, seis amostras apresentaram contaminação por ovos de Toxocara spp. No entanto, apesar da importância deste estudo, não foram realizadas novas investigações sobre contaminação do solo por geo-helmintos neste município nos últimos vinte anos.

Desta forma, o objetivo deste trabalho foi investigar a contaminação do solo por geo-helmintos em praças do município de Botucatu-SP, identificando a prevalência dos principais gêneros e sua ocorrência em um numero ampliado praças de diferentes áreas do município.

\section{Métodos}

O estudo foi realizado com amostras de solo (terra ou areia), coletadas em praças do município de Botucatu, SP. As praças foram catalogadas e distribuídas entre as regiões administrativas (norte, sul, leste, oeste e central) de acordo com mapa participativo municipal.

Para a estimativa do número do número de amostras de solo, foi considerada a prevalência de $17,5 \%$ de geo-helmintos, a partir de dados obtidos por Santarém et al. ${ }^{10}$ no mesmo município, com intervalo de confiança (IC) de $90 \%$ para atingir o número de 30 praças.

As coletas foram realizadas em dois momentos: momento I (de outubro a dezembro de 2017) e momento II (de fevereiro a março de 2018), sendo avaliadas 30 praças em cada um dos momentos. Neste período, o clima mais quente e de maior pluviosidade, cria condições favoráveis de temperatura e umidade para o desenvolvimento das espécies geo-helminticas ${ }^{5}$.

No momento I, as praças foram escolhidas por conveniência, distribuídas igualmente entre as cinco regiões administrativas do município, exceto a região oeste que possui apenas quatro praças. Desta forma, foi necessário redistribuir duas praças desta região, que foram adicionadas à região norte e à central. 
No momento II, foi realizada uma nova coleta. As praças foram escolhidas por sorteio, por meio do software livre Bioestat 5.3, de forma estratificada, distribuindo-as entre as cinco regiões administrativas. Na região oeste que possui menos praças, realizou-se um novo sorteio entre as demais regiões, sendo incluídas nas regiões sul e norte.

O estudo foi submetido ao Comitê de Ética e aprovado sob o protocolo CEUA FMVZ/UNESP, campus Botucatu 0157/2017.

Foram coletados dados de temperatura média, precipitação acumulada e umidade relativa dos períodos em que o estudo foi realizado, a partir dos dados obtidos pela estação metereológica da Universidade Estadual Paulista "Júlio de Mesquita Filho"- Faculdade de Ciências Agrárias, UNESP, campus Botucatu.

As amostras de solo foram coletadas aleatoriamente, com o auxílio de uma pá de jardinagem, obtendo-se um pool de amostras de cinco pontos diferentes de cada praça, respeitando uma distância mínima de cinco metros de qualquer amostra fecal. Antes de coletar amostras de uma nova praça o material de coleta foi devidamente higienizado e seco. As amostras de terra e/ou areia contendo aproximadamente 250 gramas, foram acondicionadas em sacos plásticos ${ }^{10}$ e encaminhadas ao Laboratório de Enfermidades Parasitárias dos Animais "Prof. Dr. Mauro Rodrigues de Oliveira" da FMVZ/UNESP, campus Botucatu.

Quando houve a presença de fezes nas praças, estas foram coletadas separadamente, em uma quantidade de aproximadamente 10 gramas, com 0 auxílio de palitos de madeira, acondicionadas em coletores universais, identificadas e mantidas sob refrigeração até a análise laboratorial.

As amostras de solo (terra e areia) e fezes foram processadas no Laboratório de Enfermidades Parasitárias dos Animais "Prof. Dr. Mauro Rodrigues de Oliveira" da Universidade Estadual Paulista "Júlio de Mesquita Filho"- FMVZ, UNESP, campus Botucatu.

Para a pesquisa de ovos de geo-helmintos, foram utilizados 10 gramas de cada amostra de solo para o processamento pela técnica modificada de centrífugo-sedimentação ${ }^{11}$. As alíquotas resultantes deste procedimento foram 
filtradas em peneiras de diâmetros $0,30 \mathrm{~mm}, 0,23 \mathrm{~mm}, 0,09 \mathrm{~mm}$ e 0,063 mm e lavadas em água corrente por 30 minutos. $O$ sedimento presente na peneira de $0,063 \mathrm{~mm}$ foi transferido para dois tubos tipo falcon de centrifugação com auxílio de uma pipeta de Pasteur. Foram então centrifugados por cinco minutos a 2000 rpm (modelo Centrífuga Baby® - Modelo 206-BL, do fabricante FANEM (®). Após a centrifugação, do primeiro tubo transferiu-se uma alíquota de 100 $\mu \mathrm{L}$ do sedimento para uma lâmina que foi avaliada sob microscopia ótica. De cada sedimento foram realizadas dez repetições de leitura (objetivas de 10x e $40 \mathrm{x})^{10}$. Do segundo tubo, os sedimentos foram processados pela técnica de centrífugo-flutuação em solução de sulfato de zinco $^{12}$, densidade 1:1350, e observados em microscopia ótica (objetivas de 10x e 40x) com três repetições do processamento de cada sedimento ${ }^{10-13}$.

O método de Baermann-Moraes (1948) ${ }^{14}$ foi utilizado para investigar a presença de larvas de Strongyloides stercoralis e também larvas de ancilostomídeos. Dez gramas de solo foram envoltos em uma gaze dobrada em quatro, perfazendo uma pequena "trouxa". O material foi colocado em cálice de sedimentação, onde foi adicionada água aquecida (45을 $\mathrm{C}$, em quantidade suficiente para entrar em contato com a amostra, que permaneceu em repouso por 12 horas. Após este período de repouso retirou-se cuidadosamente a gaze e coletou-se o sedimento presente no fundo do cálice, com a ajuda de uma pipeta de Pasteur e examinadas no microscópio ótico (objetiva 10x), em cinco repetições, de acordo com as modificações propostas por RUGAl et al. $(1954)^{15}$.

Duas a cinco gramas de cada amostra de fezes foram processadas por meio de técnica de flutuação simples ${ }^{16}$, com utilização de solução hipersaturada de cloreto de sódio $(\mathrm{NaCl})$. As lâminas foram examinadas no microscópio ótico (objetiva 10x) para pesquisa de elementos parasitários.

Foram determinados os fatores de risco para a contaminação do solo por geo-helmintos a partir de dados previamente publicados na literatura ${ }^{10-17-18-}$ ${ }^{19-20}$, setor de localização da praça, presença de seres humanos, estado de conservação, tipo de solo, presença de animais, local de coleta de amostra, 
presença de fezes no local e a técnica laboratorial utilizada para processamento das amostras.

Para a avaliação da associação das diversas variáveis qualitativas (fatores de risco) das praças em relação à presença de ovos de geo-helmintos e devido ao tamanho da amostragem, além da possibilidade de diferença da frequência entre os dados, utilizou-se o Teste Exato de Fisher (TEF). Os valores de $p$ resultantes do Teste Exato de Fisher que apresentaram valores significativos $(p<0,001)$ foram utilizados para o modelo de regressão logística, observando a razão de chances (OR- Odds Ratio) da contaminação por geohelmintos no solo das praças investigadas.

As análises estatísticas foram realizadas no software estatístico SAS, em versão on-line utilizando-se o modelo de regressão logística (função Proc $\mathrm{glm}$ ), bem como seu diagnóstico. O nível de significância considerado foi de $\mathrm{p}<0,05$.

\section{Resultados e Discussão}

Os resultados obtidos demonstraram a presença de ovos da superfamília Ancylostomatoidea e de ovos do gênero Toxocara, nas amostras de terra das praças do muncípio de Botucatu, SP. Nas amostras de areia e fezes coletadas neste estudo, não foram observados ovos e/ou larvas de geohelmintos.

A partir das análises das amostras do solo(terra) obtidas nas praças estudadas, foram observados ovos do gênero Toxocara e ovos de ancilostomídeos (Tabelas 1 e 2), sendo este último encontrado somente nas coletas realizadas no momento II em duas praças.

Em relação as condições climáticas, não houve variação significativa de temperatura média, precipitação acumulada e umidade relativa do ar entre os períodos estudados (Tabela 3).

Devido à baixa frequência de ovos de ancilostomídeos, foram analisados somente os dados de contaminação por ovos de Toxocara spp. A avaliação dos dados, pelo Teste Exato de Fischer (TEF), por meio de análise univariada (presença ou ausência de ovos de Toxocara spp.) dos fatores de risco, 
demonstrou que o setor de localização das praças, a presença de fezes nas praças e a técnica utilizada para o processamento das amostras de solo, estiveram significativamente associadas à contaminação por ovos de Toxocara spp. (Tabela 4).

A partir dos resultados obtidos pelo TEF, foi aplicado o modelo de regressão logística em relação aos setores de localização das praças, presença de fezes e a técnica laboratorial utilizada para o processamento das amostras de solo. Desta forma, em relação razão das chances $(O R)$ estimados por modelo ajustado, a presença de fezes nas praças foi o único fator de risco que apresentou associação significativa $(p=0,0022)$ com a possibilidade de encontrar ovos do gênero Toxocara spp. (Tabela 5).

Nas praças em que houve a presença de fezes, a chance de contaminação por ovos de Toxocara spp. foi 10,2 vezes maior do que nas praças que não apresentaram fezes, considerando-se as demais variáveis como constantes.

Os resultados obtidos no presente estudo demonstraram que o risco de contaminação de seres humanos por ovos de Toxocara spp. esteve presente, pois foi o geo-helminto mais prevalente (Tabela 2), para a população que frequenta as praças e os parques públicos no município de Botucatu, onde 0 acesso de cães e gatos é comum.

O principal fator de risco observado e relacionado com a presença de ovos de Toxocara spp. nos locais investigados, foi a presença de fezes de animais nos ambientes avaliados (Tabela 4). Entre os fatores de risco relacionados com a presença de geo-hemintos, as fezes de cães e gatos no ambiente podem ser consideradas como fator relevante de contaminação, em virtude do livre acesso dos animais em locais públicos, promovendo um ambiente favorável ao desenvolvimento do ciclo do parasita e uma possível contaminação dos seres humanos ${ }^{17-21}$. De acordo com Traversa et al. ${ }^{22}$, os principais fatores relacionados com a presença de fezes de animais de companhia em locais públicos, são limitações em programas de controle populacional de animais, em programas de prevenção de parasitismo pela utilização de anti-helmínticos e a presença constante de animais nas ruas, evidenciando problemas de educação em saúde pública. 
A maior frequência de ovos de Toxocara spp. e o principal fator de risco (presença de fezes de animais) nas praças do município de Botucatu, podem ser explicados pela resistência dos ovos maduros deste ascarídeo de sobreviverem no solo, mesmo em condições adversas de umidade e temperatura, com persistência da viabilidade dos ovos por anos ${ }^{22-23}$. Desta forma, este fator de risco pode desempenhar um papel epidemiológico importante na contaminação ambiental por geo-helmintos ${ }^{20}$, uma vez que a toxocaríase é uma das doenças parasitárias de prioridade para ações de saúde pública $^{24}$.

Santarém et al. ${ }^{10}$, no município de Botucatu, também encontraram ovos do gênero Toxocara como o geo-helminto mais prevalente, além de baixa prevalência de ovos da superfamília Ancylostomatoidea. A principal diferença entre os resultados desses dois estudos realizados no município de Botucatu, se deve ao fato de que a presente investigação foi realizada vinte anos após o trabalho dos autores supracitados, com ampliação da área de estudo, pela avaliação de um número maior de praças e parques.

Em relação ao período de realização deste estudo (meses investigados) no município de Botucatu, ou seja, das estações do ano avaliadas, Santarém et al. ${ }^{10}$ também recuperaram maior número de ovos do gênero Toxocara na primavera e no verão. Da mesma forma, no município de São Paulo ${ }^{25}$, foram observados dois picos de recuperação de ovos de Toxocara spp. de amostras de solo de locais públicos, no verão e outono, entre os meses de fevereiro a maio e entre abril a junho. Porém, Tiyo et al. ${ }^{19}$ encontraram maior prevalência de ovos de Toxocara spp. em amostras recuperadas no verão e no inverno. Assim, a recuperação de ovos de Toxocara spp. do solo pode estar relacionada com condições ambientais, mas também físicas e de diferentes métodos utilizados, o que torna difícil a interpretação de variações sazonais sobre a contaminação do solo por ovos deste gênero ${ }^{5-6-23}$.

A maior prevalência do gênero Toxocara no solo de Botucatu foi semelhante aos dados obtidos em outras regiões do estado de São Paulo, como nos municípios de Fernandópolis ${ }^{17}$, São Paulo ${ }^{25}$, Presidente Prudente ${ }^{26}$, Guarulhos ${ }^{27}$, onde as amostras de solo provenientes de parques e praças públicas apresentaram alta prevalência deste gênero em relação a outros geohelmintos. 
Por outro lado, em amostras de fezes de canteiros da orla marítima do município de Praia Grande ${ }^{28}$, a prevalência de ovos de Toxocara spp. foi baixa, discordando dos estudos supracitados, sugerindo que a membrana espessa dos ovos deste gênero protege a larva infectante, fazendo com que os ovos resistam no solo por longos períodos.

Nas amostras de areia coletadas neste estudo, não foram observados ovos e/ou larvas de geo-helmintos, diferentemente dos resultados obtidos em amostras de areia de escolas e creches do município de Araraquara, que indicaram alta prevalência de larvas do gênero Ancylostoma ${ }^{29}$, demonstrando, neste caso, a possibilidade de contaminação do solo por fezes de gatos, colocando em risco a saúde das crianças que frequentam esses locais.

No estado do Paraná, Tiyo et al. ${ }^{19}$ e Chieffi e Muller $^{22}$, também observaram maior prevalência do gênero Toxocara, nos municípios de Maringá e Londrina, respectivamente. Entretanto, no município de Lavras, estado de Minas Gerais, o gênero Ancylostoma foi o geo-helminto de maior prevalência $^{30}$.

O panorama de contaminação do solo por ovos de geohelmintos, em especial por ovos de Toxocara spp, no Brasil, ainda não é totalmente conhecido, apesar de diversos estudos realizados, há escassez de registros na literatura em algumas unidades federativas do país.

Os resultados do presente estudo demonstraram que ainda existem deficiências nas politicas de saúde pública do município. No entanto, este cenário representa tanto as condições locais como as de grande parte dos munícipios brasileiros que ainda são deficientes em ações estratégicas no controle dos geo-helmintos, seja no controle do acesso a cães e gatos errantes e/ou domiciliados às praças e parques públicos, ou na conscientização da população em relação aos riscos que a presença de fezes de animais nesses locais representam risco à saúde humana. 


\section{Considerações finais}

Amostras de solo de praças de Botucatu apresentaram alta prevalência de ovos de Toxocara spp. e o principal fator de risco de contaminação do solo foi a presença de fezes de animais nos locais avaliados. Desta forma, são necessárias políticas de saúde pública para evitar a contaminação da população humana que frequenta esses locais, combinando abordagens para prevenir a contaminação do solo por geo-helmintos e controlar as geohelmintíases uma vez que não são doenças de notificação compulsória no Brasil. Neste cenário o papel, o médico veterinários é de grande importância, contribuindo para a inclusão dos exames coproparasitológicos à rotina, além de ser um importante agente de conscientização da população sobre os riscos da contaminação por geo-helmintos. 


\section{Referências}

1. Chieffi PC, Amato-Neto V. Vermes, verminoses e a saúde pública. Rev Cienc . Cult. 2003; 55(1): 41-43.

2. Jia TW, Melville S, Utzinger J, King $\mathrm{CH}$, Zhou XN . Soil-Transmitted Helminth Reinfection after Drug Treatment: A Systematic Review and Metaanalysis. PLoS Negl Trop Dis. 2012 6(5): e1621. DOI:10.1371/journal.pntd.0001621.

3. Mota, KCP, Grama DF, Fava NMN, Úngari LP, Faria ESM, Cury MC. Distribution and risk factors of Ascarididae and other geohelminths in the soil of Uberlandia, Minas Gerais, Brazil. Rev Inst Med Trop São Paulo. 2018;60:e17. DOI: 10.1590/s1678-9946201860017.

4. Hotez PJ, Bundy DAP, Beegle K, et al, editors. Helminth infections: soiltransmitted helminth infections and Schistosomiasis. 2006 In: Disease control priorities in developing countries, $2^{\text {nd }}$ ed., World Bank Publications; 467-482.

5. Chieffi PP. Helmintoses e alterações ambientais e climáticas. Arq Med Hosp Fac Cienc Med Santa Casa São Paulo. 2015; 60: 27-31.

6. Etewa SE, Abdel-Rahman SA, Abd El-Aal NF, Fathy GM, El-Shafey MA, Ewis AMG. 630 Geohelminths distribution as affected by soil properties, physicochemical factors and 631 climate in Sharkyia governorate Egypt. $J$ Parasit Dis Off Organ Indian Soc Parasitol.2016;40:496-504. DOI:10.1007/s12639-014-0532-5.

7. Hotez PJ, Kamath A. Neglected tropical diseases in sub-Saharan Africa: review of their prevalence, distribution, and disease burden. PLoS Negl Trop Dis. 2009; 3: e412.

8. Ojha SC, Jaide C, Jinawath N, Rotjanapan P, Baral P. Geohelminths: public health significance.. J Infect Dev Ctries .2014; 8(1):005-016. DOI:10.3855/jidc.3183

9. Magnaval JF, Glickman LT, Dorchies P, Morassin B. Highlights of human toxocariasis. Korean J Parasitol. 2001;39:1-11. DOI:10.3347/kjp.2001.39.1.1

10. Santarém VA, Sartor IF, Bergamo FM. Contaminação por ovos de Toxocara spp. de praças públicas de Botucatu, São Paulo, Brasil. Rev Soc Bras Med Trop. 1998;31:529-32.

11. Otero, D, Alho AM, Nijsse R, Roelfsema J, Overgaauw P, de Carvalho, L.M., 2018. Environmental contamination with Toxocara spp. eggs in public parks and playground sandpits of Greater Lisbon, Portugal. J. Infect. Public Health. 2018 (11) ,94-98. DOI :dx.doi.org/10.1016/j.jiph.2017.05.002 
12. Faust EC, D'antoni JS, Odom V, Miller MJ, Peres C, Sawitz W, Thomen LF, Tobie J, Walker JH 1938. A critical study of clinical laboratory techniques of the diagnosis of protozoan cysts and helminth eggs in feces. I - Preliminary communication. Am J Trop Med Hyg 18: 169-183.

13. Dada BJ, Lindquist WD. Prevalence of Toxocara spp. eggs in some public grounds and highway rest areas in Kansas. J Helminthol. 1979;53:145-6

14. Moraes RG. Contribuição para o estudo do Strongyloides stercoralis e da estrongiloidíase no Brasil. Rev Serv Saúde Pública. 1948, 1: 507-624.

15. Rugai E, Mattos T, Brisola AP. Nova técnica para isolar larvas de nematóides das fezes: modificação do método de Baermann. Rev Inst Adolfo Lutz. 1954;14:5-8.

16. Willis, $\mathrm{HH}$. A simple levitation method for the detection of hookworm ova. Med J Aust. 1921, 2:375-376, 29: 375-376.

17. Cassenote AJF, Neto JMP, Lima-Catelani ARA, Ferreira AW. Contaminação do solo por geo-helmintos na Cidade de Fernandópolis-SP. Rev Soc Bras Med Trop 2011; 44(3):371-374.

18. Capuano DM, Rocha GM. Environmental contamination by Toxocara sp. eggs in Ribeirão Preto, São Paulo State, Brazil. Rev Inst Med Trop Sao Paulo 2005; 47(4)223-226.

19. Tiyo R, Guedes TA, Falavigna DL, Falavigna-Guilherme AL. Seasonal contamination of public squares and lawns by parasites with zoonotic potential in southern Brazil. $J$ Helminthol. 2008;82:1-6. DOI : http://dx.doi.org/10.1017/S0022149X07870829

20. Scaini C, Toledo R, Lovatel R, Dionello M, DosAnjos-Gatti F, Susin L, Signorini V. Environmental contamination by helminth eggs and larvae in dog feces from central area of cassino beach, Rio Grande do Sul. Rev. Soc. Bras. Med. Trop. 2003 ,36(5):617-619.

21. Chieffi PP, Müller EE. Prevalência de parasitismo por Toxocara canis em cães e presença de ovos de Toxocara sp. no solo de localidades públicas da zona urbana do município de Londrina, Estado do Paraná, Brasil. Rev Saúde Pública 1976; 10:367-72.

22. Traversa D, Regalbono AF, Cesare A, Torre FL, Drake J, Pietrobelli M. Environmental contamination by canine geohelminths. Parasit \& Vectors . 2014 7: 67. DOI: https://doi.org/10.1186/1756-3305-7-67

23. Kirchheimer R, Jacobs DE. Toxocara species egg contamination of soil from children's play areas in southern England. Vet. Rec. 2008, 163, 394-395. DOI: http://dx.doi.org/10.1136/vr.163.13.394. 
24. CDC-CENTER FOR DISEASE CONTROL AND PREVENTION. Guidelines for veterinarians:prevention of zoonotic transmission of ascarids and hookworms of dogs and cats.[Acesso em: 15 junho 2018]

Disponível em: http://www.cdc.gov/ncidod/dpd/parasites/ascaris/prevention.pdf

25. Queiroz MLD, Simonsen M, Paschoalotti MA, Chieffi PP. Frequency of soil contamination by Toxocara canis eggs in the south region of São Paulo municipality (SP, Brazil) in a 18 month period. Rev Inst Med Trop Sao Paulo. 2006, 48(6), 317-319.

26. Santarém VA, Pereira VC, Alegre BCP. Contamination of public parks in Presidente Prudente (São Paulo, Brazil) by Toxocara spp. eggs. Rev. Bras. Parasitol. Vet. 2012, Jaboticabal, 21(3), 323-325.

27. Marques JP, Guimarães CR, Boas AV, Carnaúba PU, Moraes J: Contamination of public parks and squares from Guarulhos (São Paulo State, Brazil) by Toxocara spp. and Ancylostoma spp. Rev Inst Med Trop Sao Paulo. 2012, 54: 267-271. DOI: http://dx.doi.org/10.1590/S0036-46652012000500006

28. Castro JM, dos Santos SV, Monteiro NA. Contaminação de canteiros da orla marítima do Município de Praia Grande, São Paulo, por ovos de Ancylostoma e Toxocara em fezes de cães. Rev Soc Bras Med Trop. 2005;38:199-201.

29. Nunes CM, Pena FC, Negrelli GB, Anjo CG, Nakano MM, Stobbe NS. Ocorrência de larva migrans na areia de áreas de lazer das escolas municipais de ensino infantil, Araçatuba, SP, Brasil. Rev Saúde Pública. 2000;34:656-8.

30. Guimarães AM, Alves EG, de Rezende GF, Rodrigues MC. Ovos de Toxocara sp. e larvas de Ancylostoma sp. em praça pública de Lavras, MG. Rev Saúde Pública. 2005;39:293-5. 
Tabela 1- Frequência da presença de ovos Toxocara spp.em amostras de solo nos momentos I (2017) e II (2018), nas praças do município de Botucatu, SP

\begin{tabular}{ccc}
\hline \multirow{2}{*}{ Toxocara } & \multicolumn{2}{c}{ Momento } \\
\cline { 2 - 3 } & $\mathrm{I}$ & $\mathrm{II}$ \\
\hline Presença & $6(17,7 \%)$ & $7(23,3 \%)$ \\
Ausência & $28(83,3 \%)$ & $23(77,7 \%)$ \\
\hline
\end{tabular}

Tabela 2- Frequência da presença de ovos ancilostomídeos em amostras de solo nos momentos I (2017) e II (2018), nas praças do município de Botucatu,SP

\begin{tabular}{ccc}
\hline \multirow{2}{*}{ Ancilostomídeos } & \multicolumn{3}{c}{ Momento } \\
\cline { 2 - 3 } & \multicolumn{2}{c}{ I } \\
\hline Presença & $0(0,0 \%)$ & II \\
Ausência & $34(100 \%)$ & $28(93,4 \%)$ \\
\hline
\end{tabular}

Tabela 3- Dados de temperatura média, precipitação acumulada e umidade relativa do ar dos nos momentos I (2017) e II (2018), do município de Botucatu, $\mathrm{SP}$

\begin{tabular}{lccc}
\hline & $\begin{array}{c}\text { Temperatura média } \\
\left({ }^{\circ} \mathrm{C}\right) \pm \mathrm{dp}^{*}\end{array}$ & $\begin{array}{c}\text { Precipitação } \\
\text { Acumulada } \\
(\mathrm{mm})\end{array}$ & $\begin{array}{c}\text { Umidade relativa do ar } \\
\text { (média) } \\
(\%)\end{array}$ \\
\hline Momento I & $21,6 \pm 2,6$ & 524,9 & 71,1 \\
Momento II & $22,5 \pm 2,6$ & 419,7 & 76,2 \\
\hline${ }^{*}$ Desvio Padrão & & &
\end{tabular}


Tabela 4- Análise univariada dos fatores de risco para presença de ovos de Toxocara spp. em amostras de solo de praças de Botucatu, SP.

\begin{tabular}{|c|c|c|c|c|c|}
\hline \multicolumn{2}{|c|}{ Fatores de Risco } & $\mathbf{N}$ & $\%$ & Total & Valor $p^{*}$ \\
\hline \multirow[t]{6}{*}{ Setor } & & & & & $<0,001^{*}$ \\
\hline & Central & 1 & 7,69 & 13 & \\
\hline & Leste & 0 & 0,00 & 14 & \\
\hline & Norte & 8 & 53,33 & 15 & \\
\hline & Oeste & 2 & 25,00 & 8 & \\
\hline & Sul & 0 & 0,00 & 14 & \\
\hline \multirow[t]{4}{*}{ Limpeza } & & & & & 0,803 \\
\hline & Adequada & 9 & 19,47 & 46 & \\
\hline & Regular & 2 & 12,50 & 16 & \\
\hline & Precária & 0 & 0,00 & 2 & \\
\hline \multirow[t]{3}{*}{ Areia/ Terra } & & & & & 0,188 \\
\hline & Ausência & 0 & 0,00 & 10 & \\
\hline & Presença & 11 & 20,37 & 54 & \\
\hline \multirow{3}{*}{ Grama } & & & & & 0,579 \\
\hline & Ausência & 11 & 18,97 & 58 & \\
\hline & Presença & 0 & 0,00 & 6 & \\
\hline \multirow[t]{4}{*}{ Cães } & & & & & 0,505 \\
\hline & Nenhum & 5 & 13,51 & 37 & \\
\hline & 1 a 5 & 6 & 22,22 & 26 & \\
\hline & Mais de 5 & 4 & 16,00 & 25 & \\
\hline \multirow[t]{3}{*}{ Gatos } & & & & & 0,770 \\
\hline & Ausência & 6 & 17,14 & 35 & \\
\hline & Presença & 1 & 25,00 & 4 & \\
\hline \multirow{3}{*}{ Fezes } & & & & & 0,683 \\
\hline & Ausência & 11 & 17,74 & 62 & \\
\hline & Presença & 0 & 0,00 & 2 & \\
\hline \multirow[t]{4}{*}{ Humanos } & & & & & $<0,001$ * \\
\hline & Nenhum & 3 & 6,67 & 45 & \\
\hline & 1 a 5 & 8 & 42,11 & 19 & \\
\hline & Mais de 5 & 2 & 13,33 & 15 & \\
\hline \multirow[t]{3}{*}{ Crianças } & & & & & 0,636 \\
\hline & Ausência & 3 & 12,50 & 24 & \\
\hline & Presença & 6 & 24,00 & 25 & \\
\hline \multirow{3}{*}{ Playgrounds } & & & & & 0,306 \\
\hline & Ausência & 2 & 14,29 & 14 & \\
\hline & Presença & 9 & 18,00 & 50 & \\
\hline \multirow[t]{3}{*}{ Local } & & & & & 0,115 \\
\hline & Ausência & 3 & 10,34 & 29 & \\
\hline & Presença & 8 & 22,86 & 35 & \\
\hline \multirow{3}{*}{ Técnica } & & & & & 0,127 \\
\hline & Flutuacãa & 4 & 11,76 & 34 & \\
\hline & Sedimentação & 7 & 23,33 & 30 & \\
\hline
\end{tabular}


Tabela 5- Variável de risco (presença de fezes) associada à presença de ovos Toxocara spp. nas amostras de solo das praças do município de Botucatu, SP

\begin{tabular}{|c|c|c|c|c|c|}
\hline Variáveis & Estimativa & $\begin{array}{c}\text { Erro } \\
\text { Padrão }\end{array}$ & $\begin{array}{c}\text { Valor } \\
\mathbf{P}\end{array}$ & $O R^{1}$ & $95 \% I^{2}{ }^{2}$ \\
\hline Intercepto & -1.48 & 0.38 & - & - & - \\
\hline Fezes & - & - & 0.0022 & - & - \\
\hline Presentes & -1.16 & 0.38 & - & 10.204 & $2.31-45.45$ \\
\hline Ausentes & Referência & - & - & Referência & - \\
\hline
\end{tabular}




\section{CONCLUSÃO GERAL}

Amostras de solo de praças de Botucatu apresentaram alta prevalência de ovos de Toxocara spp. e o principal fator de risco de contaminação do solo foi a presença de fezes de animais nos locais avaliados. Neste cenário, políticas de saúde pública são necessárias para a redução e para evitar a contaminação da população humana que frequenta esses locais. Desta forma, além dos médicos veterinários, que podem contribuir para incrementar a rotina de exames coproparasitológicos e a comunidade deve exercer o papel de agente de saúde, combinando abordagens para prevenir a contaminação do solo por geo-helmintos e controlar as geohelmintíases na população. 
Anexos 
Tabela 1- Praças do município de Botucatu avaliadas nos momento I (2017)

\begin{tabular}{|c|c|c|}
\hline ID Nome & Região & Setor \\
\hline 1 Praca Isabel Arruda - Centro & $\mathrm{R} 1$ & Central \\
\hline 2 Praça Coronel Moura - Paratodos- Centro & $\mathrm{R} 1$ & Central \\
\hline 3 Praça Comendador Emílio Pedutti ("Praça do Bosque")- Centro & R1 & Central \\
\hline 4 Praça Rubião Junior- Centro & $\mathrm{R} 1$ & Central \\
\hline 5 Praça João Rodrigo Souza Aranha- Vila Assunção & $\mathrm{R} 2$ & Central \\
\hline 6 Praça Brasil-Japão- Vila São Judas Tadeu & R3 & Central \\
\hline 7 Praça Reverendo Antônio Correa Pinto, Vila São Lúcio & $\mathrm{R} 4$ & Central \\
\hline 8 Praça Alexandre Flemming-Vila Casa Branca & R5 & Norte \\
\hline 9 Praça Dom Pedro I - Vila Antática & R6 & Norte \\
\hline 10 Baptista Butignoli - Vila Nova Botucatu & $\mathrm{R} 8$ & Norte \\
\hline 11 Praça Dona Chiquita - Jardim Panorama & $\mathrm{R} 8$ & Norte \\
\hline 12 Praça Poliesportiva Monte Mor & R9 & Norte \\
\hline 13 Praça do Abolicionista & $\mathrm{R} 10$ & Norte \\
\hline 14 Praça Isaltino Pinheiro de Castro- Jardim Paraiso & $\mathrm{R} 10$ & Norte \\
\hline 15 Parque Municipal - “Joaquim Amaral Amando de Barros" - Jd. Paraiso & $\mathrm{R} 10$ & Norte \\
\hline 16 Praça Salim Raphael Abud- Jardim Cristina & $\mathrm{R} 11$ & Leste \\
\hline 17 Praça Serafim da Costa Carreira - Jardim Peabiru & $\mathrm{R} 12$ & Leste \\
\hline 18 Praça Botumirim - Jardim Ciranda & $\mathrm{R} 12$ & Leste \\
\hline 19 Praça Dom Pedro II - Bairro Alto & $\mathrm{R} 13$ & Leste \\
\hline 20 Praça Prof ${ }^{\mathrm{a}}$ Marina de Passos- Jardim Peabiru & $\mathrm{R} 12$ & Leste \\
\hline 21 Ginasio Municipal Governador Mário Covas- Jardim Ypiranga & $\mathrm{R} 13$ & Leste \\
\hline 22 Praça Rogério Rúbio- Conjunto Habitacional Roque Ortiz Filho (Comerciários) & $\mathrm{R} 14$ & Sul \\
\hline 23 Praça Rotaty Clube - Jardim Reflorenda & $\mathrm{R} 15$ & Sul \\
\hline 24 Praça Padre Bento - Conjunto Habitacio Humberto Popolo (Cohab I) & $\mathrm{R} 15$ & Sul \\
\hline 25 Praça Jorge Bruder, Conjunto Habitacio Humberto Popolo (Cohab I) & $\mathrm{R} 15$ & Sul \\
\hline 26 Praça Antonio Ramos da Silva- Prque dos Pinheiros & $\mathrm{R} 16$ & Sul \\
\hline 27 Praça José Pires de Arruda- Residencial Lívia & $\mathrm{R} 17$ & Oeste \\
\hline 28 Praça lole Dinucci Fernandes- Jardim Riviera (Fórum) & $\mathrm{R} 18$ & Oeste \\
\hline 29 Praça Aristóteles Albertini (TOTE) -Jardim tropical & R19 & Oeste \\
\hline 30 Praça José de Souza Nogueira - Jardim Sao Jose (Rubiao Junior) & $\mathrm{R} 20$ & Oeste \\
\hline
\end{tabular}


Tabela 2- $\quad$ Praças do município de Botucatu avaliadas no momento II (2018)

\begin{tabular}{|c|c|c|c|c|}
\hline & ID & Nome & Região & Setor \\
\hline & 1 & Praça Antonio Frederico Ozanam & R1 & Central \\
\hline $\mathbf{R}$ & 2 & Praça Cel. Raphael Augusto De Moura (Paratodos) & $\mathrm{R} 1$ & Central \\
\hline $\mathbf{R}$ & 3 & Praça Emilio Pedutti Comendador (Bosque) & $\mathrm{R} 1$ & Central \\
\hline \multirow[t]{4}{*}{$\mathbf{R}$} & 4 & Praça Rubião Junior & $\mathrm{R} 1$ & Central \\
\hline & 5 & Praça Raul Gomes Pinheiro Machado & R3 & Central \\
\hline & 6 & Praça Jose Henrique Dos Reis (João Paulo) & R4 & Central \\
\hline & 7 & Praça Victorio Marigonda & $\mathrm{R} 10$ & Norte \\
\hline \multirow[t]{4}{*}{$\mathbf{R}$} & 8 & Praça Alexandre Fleming & R5 & Norte \\
\hline & 9 & Praça Antonio Cecilio & $\mathrm{R} 10$ & Norte \\
\hline & 10 & Praça Helios Monteferrante Junior & R9 & Norte \\
\hline & 11 & Praça Jose Martins (Guanxuma) & $\mathrm{R} 10$ & Norte \\
\hline $\mathbf{R}$ & 12 & Praça Poliesportiva Monte Mor & $\mathrm{R} 9$ & Norte \\
\hline \multirow[t]{3}{*}{$\mathbf{R}$} & 13 & Praça do Abolicionista & $\mathrm{R} 10$ & Norte \\
\hline & 14 & Praça Affonso De Carvalho Barros & $\mathrm{R} 13$ & Leste \\
\hline & 15 & Praça Egydio Vizzotto & $\mathrm{R} 13$ & Leste \\
\hline \multirow[t]{2}{*}{$\mathbf{R}$} & 16 & Praça Salim Raphael Abud & $\mathrm{R} 12$ & Leste \\
\hline & 17 & Praça Feud Jorge & $\mathrm{R} 12$ & Leste \\
\hline \multirow[t]{5}{*}{$\mathbf{R}$} & 18 & Praça Botumirim & $\mathrm{R} 12$ & Leste \\
\hline & 19 & Praça Demade Nelson Lunardi & $\mathrm{R} 12$ & Leste \\
\hline & 20 & Praça Paulo De Souza Teixeira & $\mathrm{R} 15$ & Sul \\
\hline & 21 & Praça Djalma Luiz Innocente, Prof ${ }^{\circ}$ & $\mathrm{R} 15$ & Sul \\
\hline & 22 & Praça Edgar Devide & $\mathrm{R} 15$ & Sul \\
\hline \multirow[t]{4}{*}{$\mathbf{R}$} & 23 & Praça Rotary Clube & $\mathrm{R} 15$ & Sul \\
\hline & 24 & Praça Lucilene Francisco & $\mathrm{R} 16$ & Sul \\
\hline & 25 & Praça Dib Jorge Saad & $\mathrm{R} 15$ & Sul \\
\hline & 26 & Praça Ligia Scolastici Mores & $\mathrm{R} 14$ & Sul \\
\hline $\mathbf{R}$ & 27 & Praça José Pires Arruda & $\mathrm{R} 17$ & Oeste \\
\hline \multirow[t]{2}{*}{$\mathbf{R}$} & 28 & Praça Iole Dinucci Fernandes & $\mathrm{R} 18$ & Oeste \\
\hline & 29 & Praça Moacir Fernandes & $\mathrm{R} 20$ & Oeste \\
\hline & 30 & Praça Jose De Souza Nogueira & $\mathrm{R} 20$ & Oeste \\
\hline
\end{tabular}




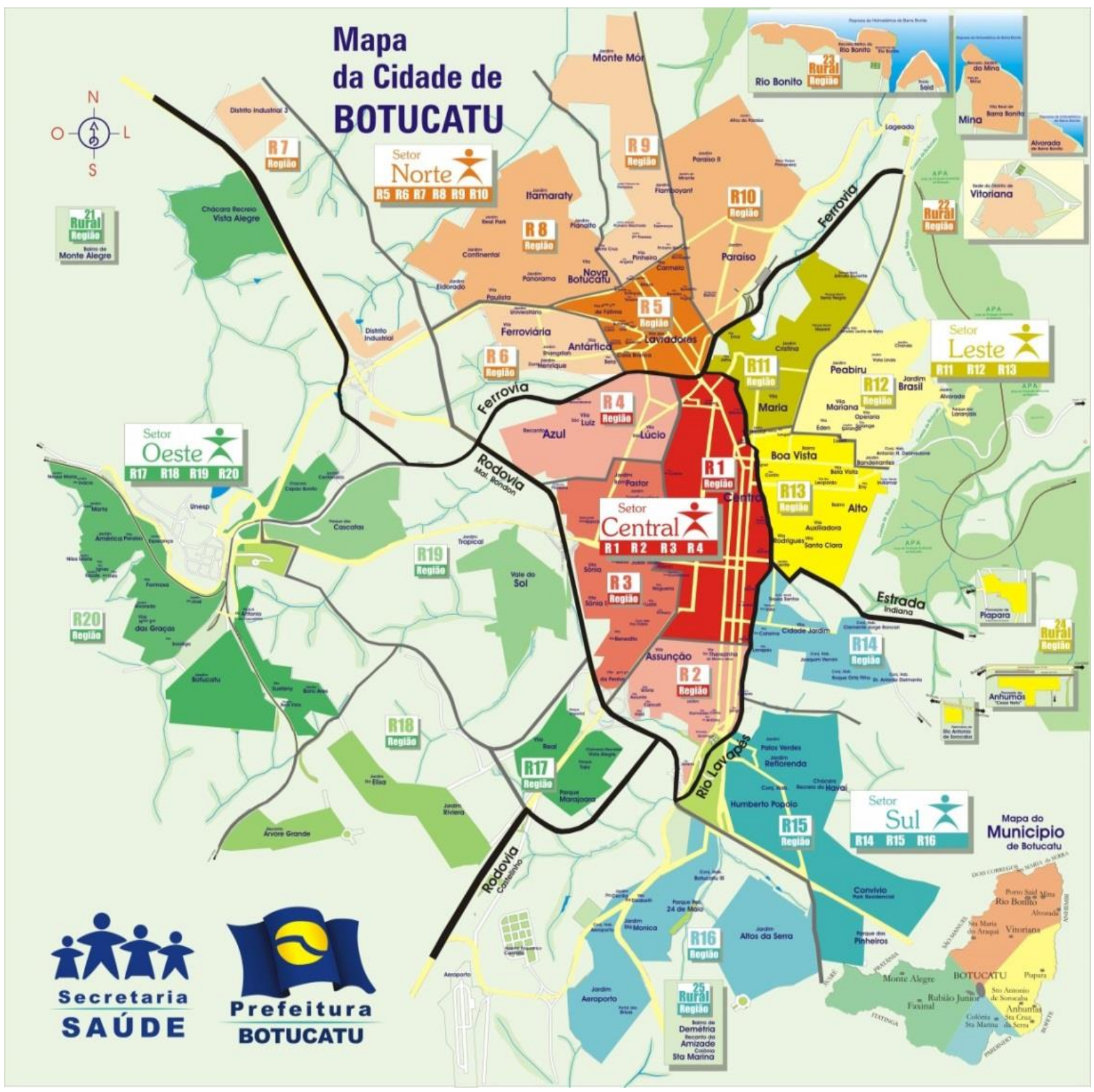

Figura 1- Mapa setorizado do município de Botucatu, SP

Fonte: PMB-Secretaria do Planejamento, 2016. 


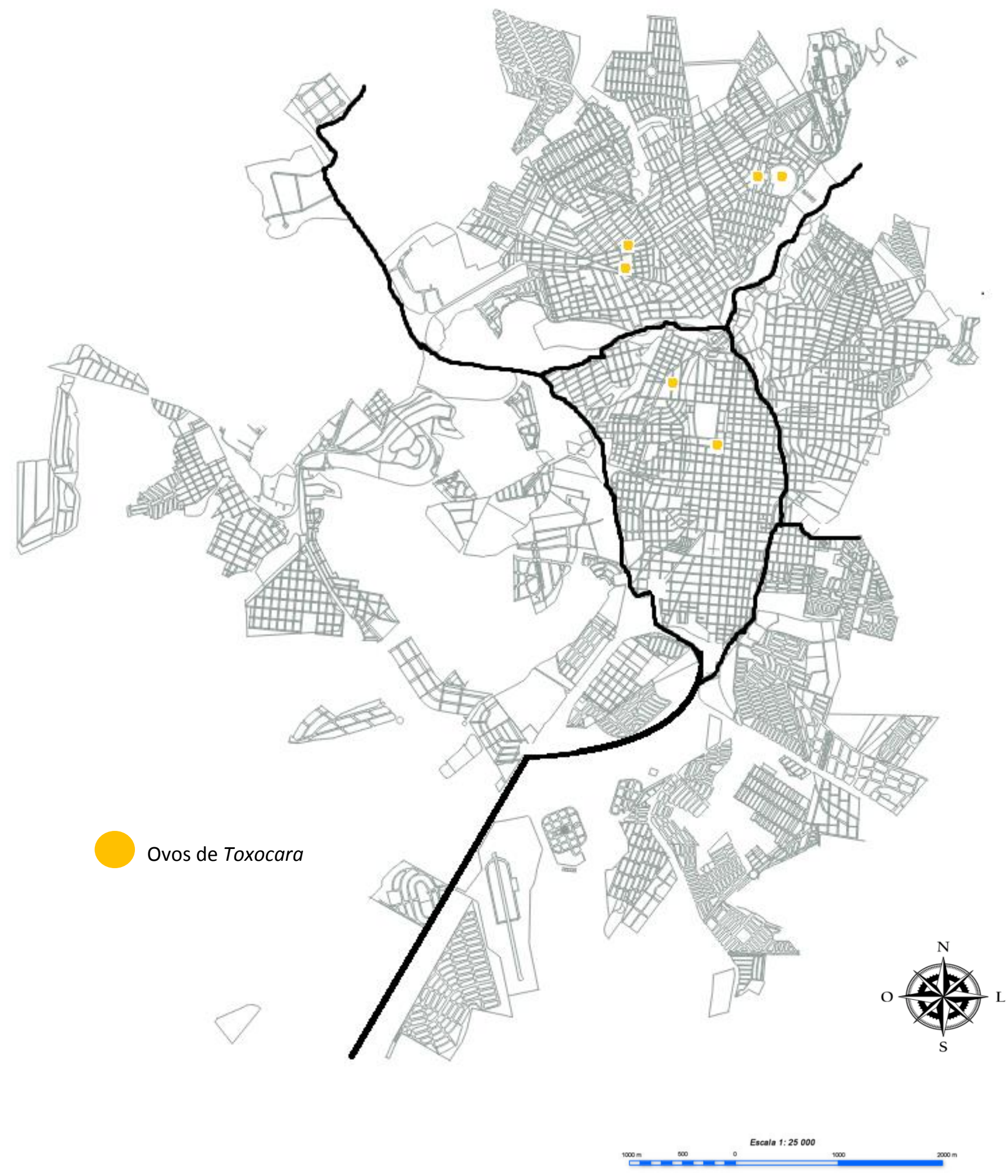

Figura 2 - Mapas com os pontos positivos para ovos Toxocara spp. no momento I 


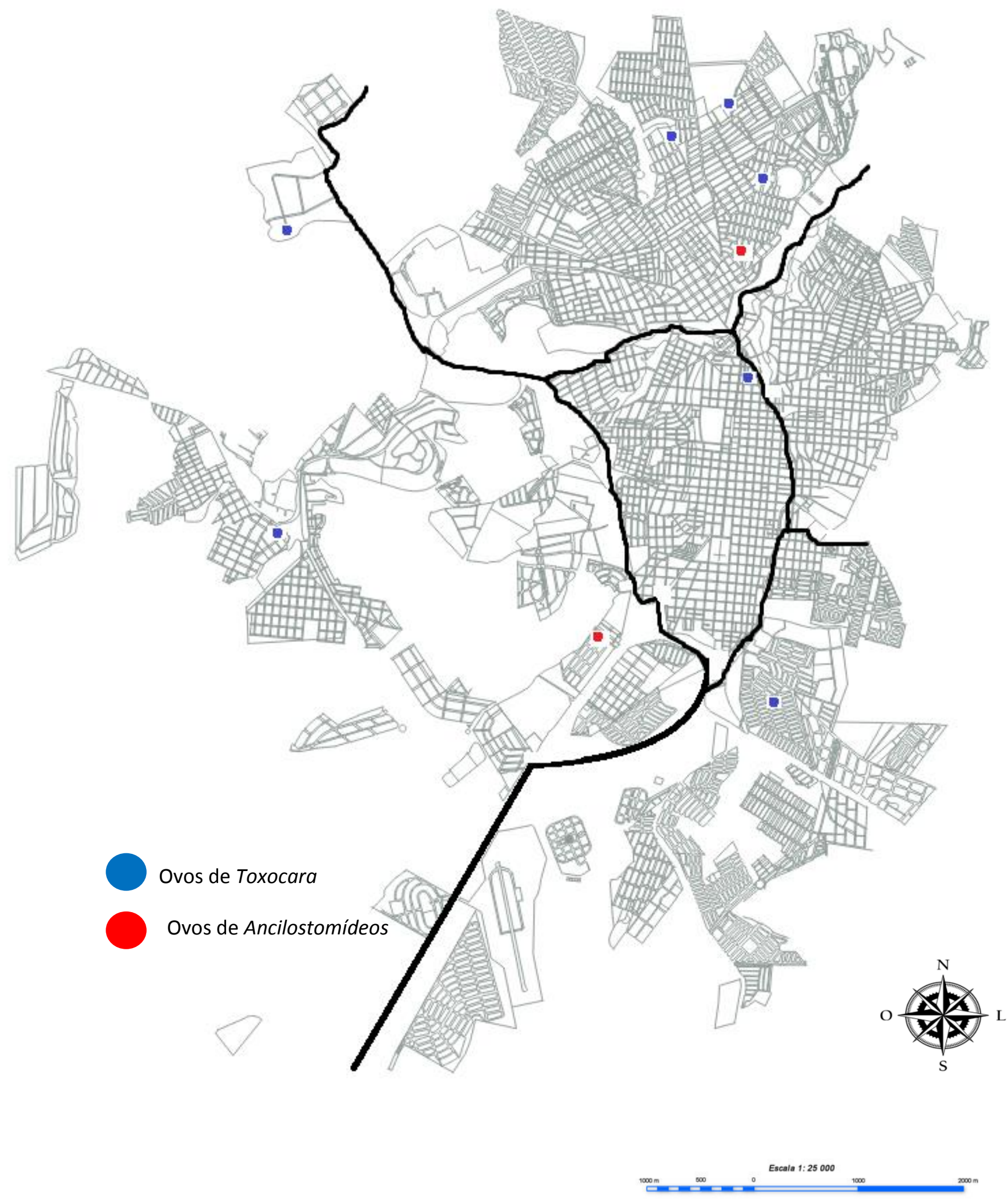

Figura 3. Mapa com os pontos positivos para ovos de Toxocara spp. (pontos azuis) e ovos de ancilostomídeos vermelhos) no momento II. 


\section{uns unesp

\section{ATESTADO}

Atesto que o Projeto "CONTAMINAÇÃO AMBIENTAL POR GEOHELMINTOS EM PRAÇAS DO MUNICÍPIO DE BOTUCATU, SÃO PAULO" Protocolo CEUA 0157/2017, a ser conduzido por Gilson Avelino Providelo, responsável/orientador Elizabeth Moreira dos Santos Schmidt, para fins de pesquisa científica/ensino - encontra-se de acordo com os preceitos da Lei no 11.794, de 08 de outubro de 2008, do Decreto $n^{\circ} \mathbf{6 . 8 9 9}$, de 15 de julho de 2009, e com as normas editadas pelo Conselho Nacional de Controle de Experimentação Animal-CONCEA.

\begin{tabular}{|c|c|}
\hline Finalidade & PESQUISA CIENTÍFICA \\
\hline Vigência do projeto & $01 / 09 / 2017$ a $31 / 08 / 2018$ \\
\hline
\end{tabular}

Projeto de Pesquisa aprovado em reunião da CEUA em 10/08/2017

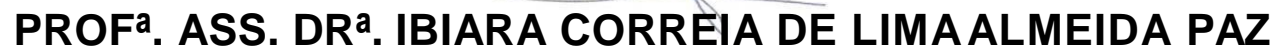

Presidente da CEUA da FMVZ, UNESP - Campus de Botucatu

Faculdade de Medicina Veterinária e Zootecnia

Seção Técnica Acadêmica

Rua Prof. Dr. Walter Mauricio Corrêa, s/n

UNESP - Campus de Botucatu/SP - Cep 18618-681

(14)3880-2176 - patrizia@fmvz.unesp.br - www.fmvz.unesp.br 
$13 / 06 / 2019$

\section{三 Revista de Saúde Pública}

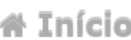

Autor

Confirmação da submissão

Bimprimir

\section{Obrigado pela sua submissão}

\section{Submetido para}

Revista de Saúde Pública

ID do manuscrito

RSP-2019-1826

Título

Contaminação ambiental por geo-helmintos em praças do município de Botucatu, São Paulo.

\section{Autores}

Providelo, Gilson

Oliveira, Raphaela

Santarém, Vamilton

Victoria, Cassiano

Pantoja, José

Schmidt, Elizabeth

Data da submissão

13-jun-2019 


\section{NORMAS DA REVISTA SAÚDE PÚBLICA

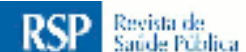 \\ INSTRUÇÕES AOS AUTORES}

\section{ISSN 0034-8910 versão}

impressa

ISSN 1518-8787 versão on-

line
- Instrução aos autores

- Categoria de artigos

- Organização do manuscrito

- Dados de identificação do manuscrito

- Conflito de interesses

- Declaração e documentos

- Preparo do manuscrito

- Estrutura do texto

- Referências

- Citação no texto

- $\quad$ Checklist para submissão

- Processo editorial

- Taxa de publicação

\section{INSTRUÇÕES AOS AUTORES}

São aceitos manuscritos nos idiomas: português, espanhol e inglês. Artigos submetidos em português ou espanhol são traduzidos para o inglês e publicados nesses dois idiomas. Para artigos submetidos em inglês, não há tradução para o português ou espanhol.

O texto de manuscrito de pesquisa original deve seguir a estrutura conhecida como IMRD: Introdução, Métodos, Resultados e Discussão (Estrutura do Texto). Manuscritos baseados em pesquisa qualitativa podem ter outros formatos, admitindo-se Resultados e Discussão em uma mesma seção e Considerações Finais ou Conclusões. Outras categorias de manuscritos (revisões, comentários etc.) seguem os formatos de texto a elas apropriados.

Os estudos devem ser apresentados de forma que qualquer pesquisador interessado possa reproduzir os resultados. Para isso, estimulamos o uso das seguintes recomendações, de acordo com a categoria do manuscrito submetido:

- CONSORT checklist e fluxograma para ensaios controlados e randomizados;

- STARD checklist e fluxograma para estudos de acurácia diagnóstica;

- MOOSE checklist e fluxograma para meta-análises e revisões sistemáticas de estudos observacionais;

- PRISMA checklist e fluxograma para revisões sistemáticas e meta-análises;

- STROBE checklist para estudos observacionais em epidemiologia;

- $\quad$ RATS checklist para estudos qualitativos.

Pormenores sobre os itens exigidos para apresentação do manuscrito estão descritos de acordo com a categoria de artigos.

Como forma de avaliação da ocorrência de plágio, todos os manuscritos recebidos são submetidos à programa de detecção de similaridades entre textos.

O ORCID do primeiro autor e de todos os coautores deverá ser informado no momento da submissão dos manuscritos, na carta de apresentação. 


\title{
Categorias de artigos
}

\section{a) Artigos Originais}

Incluem estudos observacionais, estudos experimentais ou quase-experimentais, avaliação de programas, análises de custo-efetividade, análises de decisão e estudos sobre avaliação de desempenho de testes diagnósticos para triagem populacional. Cada artigo deve conter objetivos e hipóteses claras, desenho e métodos utilizados, resultados, discussão e conclusões.

Incluem também ensaios teóricos (críticas e formulação de conhecimentos teóricos relevantes) e artigos dedicados à apresentação e discussão de aspectos metodológicos e técnicas utilizadas na pesquisa em saúde pública. Neste caso, o texto deve ser organizado em tópicos para guiar o leitor quanto aos elementos essenciais do argumento desenvolvido.

\begin{abstract}
Instrumentos de aferição em pesquisas populacionais
Manuscritos que abordem instrumentos de aferição podem incluir aspectos relativos ao desenvolvimento, à avaliação e à adaptação transcultural para uso em estudos populacionais, excluindo-se aqueles de aplicação clínica, que não atendem ao escopo da RSP.
\end{abstract}

Aos manuscritos de instrumentos de aferição, recomenda-se que seja apresentada uma apreciação detalhada do construto a ser avaliado, incluindo seu possível gradiente de intensidade e suas eventuais subdimensões. O desenvolvimento de novo instrumento deve estar amparado em revisão de literatura que identifique explicitamente a insuficiência de propostas prévias e justifique a necessidade de novo instrumental.

Devem ser detalhados: a proposição, a seleção e a confecção dos itens e o emprego de estratégias para adequá-los às definições do construto, incluindo o uso de técnicas qualitativas de pesquisa (entrevistas em profundidade, grupos focais etc.), reuniões com painéis de especialistas, entre outras; o trajeto percorrido na definição da forma de mensuração dos itens e a realização de pré-testes com seus conjuntos preliminares; e a avaliação das validades de face, conteúdo, critério, construto ou dimensional.

Análises de confiabilidade do instrumento também devem ser apresentadas e discutidas, incluindo-se medidas de consistência interna, confiabilidade testereteste ou concordância inter-observador. Os autores devem expor o processo de seleção do instrumento final e situá-lo em perspectiva crítica e comparativa com outros instrumentos destinados a avaliar o mesmo construto ou construtos semelhantes.

Para os manuscritos sobre adaptação transcultural de instrumentos de aferição, além de atender, de forma geral, às recomendações supracitadas, é necessário explicitar o modelo teórico norteador do processo. Os autores devem também justificar a escolha de determinado instrumento para adaptação a um contexto sociocultural específico, com base em minuciosa revisão de literatura. Finalmente, devem indicar explicitamente como e quais foram as etapas seguidas do modelo 
teórico de adaptação no trabalho submetido para publicação.

O instrumento de aferição deve ser incluído como anexo dos artigos submetidos.

\section{Organização do manuscrito}

Além das recomendações mencionadas, verificar as seguintes instruções de formatação:

\section{a) Artigo original}

- Devem conter até 3.500 palavras (excluindo resumos, tabelas, figuras e referências).

- Número máximo de tabelas e figuras: 5.

- Número máximo de referências: 30.

- Resumos no formato estruturado com até 300 palavras.

b) Comunicação breve - São relatos curtos de achados que apresentam interesse para a saúde pública, mas que não comportam uma análise mais abrangente e uma discussão de maior fôlego. Sua apresentação deve acompanhar as normas exigidas para artigos originais.

- Devem conter até 1.500 palavras (excluindo resumos tabelas, figuras e referências).

- Número máximo de tabelas e figuras: 1.

- Número máximo de referências: 5.

- Resumos no formato narrativo com até 100 palavras.

\section{c) Artigo de revisão}

- Revisão sistemática e meta-análise - Por meio da síntese de resultados de estudos originais, quantitativos ou qualitativos, objetiva responder a uma pergunta específica e de relevância para a saúde pública. Descreve com pormenores o processo de busca dos estudos originais, os critérios utilizados para a seleção daqueles que foram incluídos na revisão e os procedimentos empregados na síntese dos resultados obtidos pelos estudos revisados. Consultar:

- MOOSE: checklist e fluxograma para meta-análises e revisões sistemáticas de estudos observacionais;

- PRISMA: checklist e fluxograma para revisões sistemáticas e metaanálises.

- Revisão narrativa ou crítica - Apresenta caráter descritivo-discursivo e dedica-se à apresentação compreensiva e à discussão de temas de interesse científico no campo da saúde pública. Deve apresentar formulação clara de um objeto científico de interesse, argumentação lógica, crítica teórico-metodológica dos trabalhos consultados e síntese conclusiva. Deve ser elaborada por pesquisadores com experiência no campo em questão ou por especialistas de reconhecido saber.

- Deve conter até 4.000 palavras (excluindo resumos, tabelas, figuras e referências).

- Número máximo de tabelas e figuras: 5.

- Número de referências: ilimitado. 
- Resumos no formato estruturado com até 300 palavras, ou narrativo com até 150 palavras.

d) Comentários - Visam a estimular a discussão, introduzir o debate e oxigenar controvérsias sobre aspectos relevantes da saúde pública. O texto deve ser organizado em tópicos ou subitens. A introdução deve destacar o assunto e sua importância. As referências citadas devem dar sustentação aos principais aspectos abordados no artigo.

- Devem conter até 2.000 palavras (excluindo resumos, tabelas, figuras e referências).

- Número máximo de tabelas e figuras: 5.

- Número máximo de referências: 30.

- Resumos no formato narrativo com até 150 palavras.

Publicamos também Cartas Ao Editor, com até 600 palavras e até 5 referências.

\section{DADOS DE IDENTIFICAÇÃO DO MANUSCRITO}

\section{Autoria}

O conceito de autoria está baseado na contribuição substancial de cada uma das pessoas listadas como autores, no que se refere à concepção do projeto de pesquisa, análise e interpretação dos dados, redação e revisão crítica do manuscrito. A contribuição de cada autor deve ser explicitada em declaração para esta finalidade. Não se justifica a inclusão de nome de autores cuja contribuição não se enquadre nos critérios mencionados.

\section{Dados de identificação dos autores (cadastro)}

Nome e sobrenome: $O$ autor deve seguir o formato pelo qual já é indexado nas bases de dados e constante no ORCID.

Correspondência: Deve constar o nome e endereço do autor responsável para troca de correspondência.

Instituição: Podem ser incluídas até três hierarquias institucionais de afiliação (por exemplo: universidade, faculdade, departamento).

Coautores: Identificar os coautores do manuscrito pelo nome, sobrenome e instituição, conforme a ordem de autoria.

Financiamento da pesquisa: Se a pesquisa foi subvencionada, indicar o tipo de auxílio, o nome da agência financiadora e o respectivo número do processo.

Apresentação prévia: Tendo sido apresentado em reunião científica, indicar o nome do evento, local e ano da realização. 


\section{Conflito de interesses}

A confiabilidade pública no processo de revisão por pares e a credibilidade de artigos publicados dependem, em parte, de como os conflitos de interesses são administrados durante a redação, revisão por pares e tomada de decisões pelos editores.

Conflitos de interesses podem surgir quando autores, revisores ou editores possuem interesses que, aparentes ou não, possam influenciar a elaboração ou avaliação de manuscritos. O conflito de interesses pode ser de natureza pessoal, comercial, política, acadêmica ou financeira.

Quando os autores submetem um manuscrito, eles são responsáveis por reconhecer e revelar conflitos financeiros ou de outra natureza que possam ter influenciado seu trabalho. Os autores devem reconhecer no manuscrito todo o apoio financeiro para o trabalho e outras conexões financeiras ou pessoais com relação à pesquisa. O relator deve relatar aos editores quaisquer conflitos de interesses que possam influir em sua opinião sobre o manuscrito e, quando couber, deve se declarar não qualificado para revisá-lo.

Se os autores não tiverem certeza do que pode constituir um potencial conflito de interesses, devem contatar a secretaria editorial da RSP.

\section{Declarações e documentos}

Em conformidade com as diretrizes do International Committee of Medical Journal Editors (ICMJE), são solicitados documentos e declarações do(s) autor(es) para a avaliação de seu manuscrito. Observe a relação dos documentos abaixo e, nos casos em que se aplique, anexe o documento ao processo. O momento em que tais documentos serão solicitados é variável:

\begin{tabular}{|l|l|l|}
\hline Documento & Quem assina & Quando anexar \\
\hline a. Carta de Apresentação & $\begin{array}{l}\text { Todos os autores ou o } \\
\text { primeiro autor assina e } \\
\text { insere o ORCID de todos } \\
\text { os autores informados na } \\
\text { carta de apresentação. }\end{array}$ & \\
\hline $\begin{array}{l}\text { b. Declaração de Responsabilidade } \\
\text { pelos Agradecimentos }\end{array}$ & Autor responsável & Após a aprovação \\
\hline $\begin{array}{l}\text { c. Declaração de Transferência de } \\
\text { Direitos Autorais }\end{array}$ & Todos os autores & Após a aprovação \\
\hline \hline
\end{tabular}

\section{a. Carta de Apresentação}

A carta de apresentação deve ser assinada por todos os autores ou, ao menos, pelo primeiro autor. O ORCID de todos os autores deverá ser informado nessa carta. A carta de apresentação deve conter:

- Informações sobre os achados e as conclusões mais importantes do manuscrito e esclarecimento de seu significado para a saúde pública;

- Informação sobre a novidade do estudo e porque ele deve ser publicado nesta revista; 
- Menção a até três artigos, se houver, publicados pelos autores na linha de pesquisa do manuscrito;

- Atestado de exclusividade da submissão do manuscrito à RSP;

- Declaração de potenciais conflitos de interesses dos autores;

- Contribuição ao manuscrito por parte de cada autor.

Segundo o critério de autoria do International Committee of Medical Journal Editors (ICMJE), autores devem contemplar todas as seguintes condições: (1) contribuir substancialmente para a concepção e o planejamento, ou análise e interpretação dos dados; (2) contribuir significativamente na elaboração do rascunho ou na revisão crítica do conteúdo; e (3) participar da aprovação da versão final do manuscrito.

Nos casos de grupos multicêntricos ou grande número de autores terem desenvolvido o trabalho, o grupo deve identificar os indivíduos que aceitam a responsabilidade direta pelo manuscrito. Esses indivíduos devem contemplar totalmente os critérios para autoria definidos anteriormente. Nesse caso, os editores solicitarão a eles as declarações exigidas na submissão de manuscritos. 0 autor correspondente deve indicar claramente a forma de citação preferida para o nome do grupo e identificar seus membros. Estes serão listados no final do texto do artigo.

Não justificam autoria: aqueles que realizaram apenas a aquisição de financiamento, a coleta de dados ou a supervisão geral do grupo de pesquisa.

\section{b.Agradecimentos}

Devem ser mencionados os nomes de pessoas que, embora não preencham os requisitos de autoria, prestaram colaboração ao trabalho. Será preciso explicitar o motivo do agradecimento (por exemplo, consultoria científica, revisão crítica do manuscrito, coleta de dados etc). Deve haver permissão expressa dos nomeados e - autor responsável deve anexar a Declaração de Responsabilidade pelos Agradecimentos. Também pode constar agradecimentos a instituições que prestaram apoio logístico.

\section{c.Transferência de Direitos Autorais}

Todos os autores devem ler, assinar e enviar o documento transferindo os direitos autorais. $\mathrm{O}$ artigo só será liberado para publicação quando esse documento estiver de posse da RSP.

O documento de transferência de direitos autorais será solicitado após a aprovação do artigo. 


\section{PREPARO DO MANUSCRITO}

\section{Título no idioma original do manuscrito}

O título deve ser conciso e completo, contendo informações relevantes que possibilitem a recuperação do artigo nas bases de dados. O limite é de 90 caracteres, incluindo espaços.

\section{Título resumido}

É o título que constará no cabeçalho do artigo. Deve conter a essência do assunto em até 45 caracteres.

\section{Descritores}

Para manuscritos escritos em português ou espanhol, devem ser indicados entre 3 e 10 descritores extraídos do vocabulário Descritores em Ciências da Saúde (DeCS) da BVS/Bireme, no idioma original. Para manuscritos em inglês, utilizar o Medical Subject Headings (MeSH) da National Library of Medicine (EUA). Se não forem encontrados descritores adequados para a temática do manuscrito, poderão ser indicados termos livres.

\section{Resumo}

O resumo deve ser escrito em seu idioma original. As especificações quanto ao tipo de resumo estão descritas em cada uma das categorias de artigos. Como regra geral, o resumo deve incluir: objetivo do estudo, principais procedimentos metodológicos (população em estudo, local e ano de realização, métodos observacionais e analíticos), principais resultados e conclusões.

\section{Estrutura do texto}

Introdução - Deve relatar de forma sucinta o contexto e a justificativa do estudo, apoiados em referências pertinentes. $O$ objetivo do manuscrito deve estar explícito no final da Introdução.

Métodos - É imprescindível a descrição clara dos procedimentos adotados, das variáveis analisadas (com a respectiva definição, se necessário) e da hipótese a ser testada. Descrever também a população, a amostra e os instrumentos de medida, com a apresentação, se possível, de medidas de validade. É necessário que haja informações sobre a coleta e o processamento de dados. Devem ser incluídas as devidas referências para as técnicas e métodos empregados, inclusive os métodos estatísticos; é fundamental que os métodos novos ou substancialmente modificados sejam descritos, justificando-se as razões para o seu uso e mencionando-se suas limitações. Os critérios éticos de pesquisa devem ser respeitados. Os autores devem explicitar que a pesquisa foi conduzida dentro dos padrões éticos e aprovada por comitê de ética.

Resultados - É preciso que sejam apresentados em uma sequência lógica, iniciando-se com a descrição dos dados mais importantes. Tabelas e figuras devem ser restritas àquelas necessárias para argumentação e a descrição dos dados no texto deve ser restrita aos mais importantes. Os gráficos devem ser utilizados para 
destacar os resultados mais relevantes e resumir relações complexas. Dados em gráficos e tabelas não devem ser duplicados, nem repetidos no texto. Os resultados numéricos devem especificar os métodos estatísticos utilizados na análise.

Discussão - A partir dos dados obtidos e resultados alcançados, os aspectos novos e importantes observados devem ser interpretados à luz da literatura científica e das teorias existentes no campo. Argumentos e provas baseadas em comunicação de caráter pessoal ou divulgadas em documentos restritos não podem servir de apoio às argumentações do autor. Tanto as limitações do trabalho quanto suas implicações para futuras pesquisas precisam ser esclarecidas. É necessário incluir somente hipóteses e generalizações baseadas nos dados do trabalho.

As Conclusões devem finalizar esta parte, retomando o objetivo do trabalho.

\section{Referências}

Listagem: As referências devem ser normatizadas de acordo com

o estilo Vancouver - Uniform Requirements for Manuscripts Submitted to Biomedical Journals: Writing and Editing for Biomedical Publication, listadas por ordem de citação. Os títulos de periódicos devem ser referidos de forma abreviada, de acordo com o PubMed. No caso de publicações com até seis autores, todos devem ser citados; acima de seis, devem ser citados apenas os seis primeiros, seguidos da expressão latina "et al.". Referências de um mesmo autor devem ser organizadas em ordem cronológica crescente. Sempre que possível, incluir o DOI do documentado citado.

\section{Exemplos:}

\section{Artigo de periódico}

Brüggemann OM, Osis MJD, Parpinelli MA. Apoio no nascimento: percepções de profissionais e acompanhantes escolhidos pela mulher. Rev Saude Publica. 2007;41(1):44-52. https://doi.org/10.1590/S0034-89102006005000015

\section{Livro}

Wunsch Filho V, Koifman S. Tumores malignos relacionados com o trabalho. In: Mendes R, coordenador. Patologia do trabalho. 2. ed. São Paulo: Atheneu; 2003. v.2, p. 990-1040.

Foley $\mathrm{KM}$, Gelband $\mathrm{H}$, editors. Improving palliative care for cancer Washington: National Academy Press; 2001[citado 2003 jul 13] Disponível em: http://www.nap.edu/catalog.php?record_id=10149

Para outros exemplos recomendamos consultar as normas ("Citing Medicine") da National Library of Medicine, disponível em http://www.ncbi.nlm.nih.gov/bookshelf/br.fcgi?book=citmed. 


\section{Citação no texto}

É necessário que a referência seja indicada pelo seu número na listagem, na forma de expoente (sobrescrito) antes da pontuação no texto, sem uso de parênteses, colchetes ou similares. Nos casos em que a citação do nome do autor e do ano for relevante, o número da referência deve ser colocado seguido do nome do autor. Trabalhos com dois autores devem fazer referência aos dois autores ligados por " $e$ ". Nos casos de autoria múltipla, apresentar apenas o primeiro autor, seguido de "et al."

\section{Exemplos:}

A promoção da saúde da população tem como referência o artigo de Evans e Stoddart9, que considera a distribuição de renda, o desenvolvimento social e a reação individual na determinação dos processos de saúde-doença.

Segundo Lima et al.9 (2006), a prevalência de transtornos mentais em estudantes de medicina é maior do que na população em geral.

\section{Tabelas}

Devem ser apresentadas no final do texto, após as referências bibliográficas, numeradas consecutivamente com algarismos arábicos, na ordem em que foram citadas no texto. A cada uma deve-se atribuir um título breve. Não utilizar traços internos horizontais ou verticais. As notas explicativas devem ser colocadas no rodapé das tabelas e não no cabeçalho ou no título. Se houver tabela extraída de trabalho publicado previamente, os autores devem solicitar formalmente autorização da revista que a publicou para sua reprodução.

Para a composição de uma tabela legível, o número máximo é de 10 colunas, dependendo da quantidade do conteúdo de cada casela. Notas em tabelas devem ser indicadas por letras e em sobrescrito.

\section{Quadros}

Diferem das tabelas por conterem texto em vez de dados numéricos. Devem ser apresentados no final do texto, após as referências bibliográficas, numerados consecutivamente com algarismos arábicos, na ordem em que foram citados no texto. A cada um deve-se atribuir um título breve. As notas explicativas devem ser colocadas no rodapé dos quadros e não no cabeçalho ou no título. Se houver quadro extraído de trabalho publicado previamente, os autores devem solicitar formalmente autorização da revista que o publicou para sua reprodução.

\section{Figuras}

As ilustrações (fotografias, desenhos, gráficos etc.) devem ser citadas como Figuras e numeradas consecutivamente com algarismos arábicos, na ordem em que foram citadas no texto e apresentadas após as tabelas. Elas também devem conter título e legenda apresentados em sua parte inferior. Só serão admitidas para publicação figuras suficientemente claras e com qualidade digital, preferencialmente no formato vetorial. No formato JPEG, a resolução mínima deve ser de 300 dpi. Não se aceitam gráficos apresentados com as linhas de grade, e os elementos (barras, círculos) não podem apresentar volume (3D). Se houver figura extraída de trabalho publicado previamente, os autores devem solicitar formalmente autorização da revista que a publicou para sua reprodução. 


\section{Checklist para submissão}

1. Nome e instituição de afiliação de cada autor, incluindo e-mail e telefone.

2. Título, no idioma original do manuscrito, com até 90 caracteres, incluindo os espaços entre as palavras.

3. Título resumido com 45 caracteres.

4. Texto apresentado em letras arial, corpo 12, em formato Word ou similar (extensões doc, docx e rtf).

5. Resumos estruturados para trabalhos originais de pesquisa no idioma original do manuscrito.6. Resumos narrativos para manuscritos que não são de pesquisa no idioma original do manuscrito.

7. Carta de Apresentação, constando a responsabilidade de autoria. Deve ser assinada por todos os autores ou, pelo menos, pelo primeiro autor e conter o ORCID de todos os autores.

8. Nome da agência financiadora e número(s) do(s) processo(s).

9. Referências normatizadas segundo estilo Vancouver, apresentadas por ordem de citação. É necessário verificar se todas as referências estão citadas no texto.

10. Tabelas numeradas sequencialmente, com título e notas, com no máximo 10 colunas.

11. Figura no formato vetorial ou em pdf, tif, jpeg ou bmp, com resolução mínima de 300 dpi. Gráficos devem estar sem linhas de grade e sem volume.

12. Tabelas, quadros e figuras não devem exceder a cinco, no conjunto.

\section{PROCESSO EDITORIAL}

\section{a) Avaliação}

Pré-análise: o Editor Científico avalia os manuscritos com base na qualidade e interesse para a área de saúde pública e decide se seleciona o manuscrito para avaliação por pares externos ou não.

Análise por pares: se selecionado na pré-análise, o manuscrito é encaminhado a um dos Editores Associados cadastrados no sistema segundo a respectiva área de especialização. O Editor Associado seleciona os revisores (dois) de acordo com a área de especialização e envia o manuscrito para avaliação. Caso o Editor Associado considere que os pareceres recebidos são insuficientes para uma conclusão, deverá indicar outro(s) relator(es). Com base nos pareceres, o Editor Associado decide por: recusa, no caso de o manuscrito ter deficiências importantes; aceite; ou possibilidade de nova submissão, devendo neste caso indicar nos seus comentários as modificações importantes para eventual reformulação, que será reavaliada por relatores.

\section{b) Revisão da redação científica}

Para ser publicado, o manuscrito aprovado é editado por uma equipe que fará a revisão da redação científica (clareza, brevidade, objetividade e solidez), gramatical e de estilo. A RSP se reserva o direito de fazer alterações visando a uma perfeita comunicação aos leitores. O autor responsável terá acesso a todas as modificações sugeridas até a última prova enviada. 


\section{c) Provas}

O autor responsável pela correspondência receberá uma prova, em arquivo de texto (doc, docx ou rtf), com as observações e alterações feitas pela equipe de leitura técnica. O prazo para a revisão da prova é de dois dias.

Caso ainda haja dúvidas nessa prova, a equipe editorial entrará em contato para que seja feita a revisão, até que seja alcançada uma versão final do texto.

Artigos submetidos em português ou espanhol serão vertidos para o inglês. Aproximadamente 20 dias após o autor ter finalizado a prova do artigo, a RSP enviará a versão em inglês do artigo para apreciação do autor. Nessa revisão, o autor deverá atentar-se para possíveis erros de interpretação, vocabulário da área e, principalmente, equivalência de conteúdo com a versão original aprovada. 0 prazo de revisão da versão em inglês é de dois dias.

A RSP adota o sistema de publicação contínua. Dessa forma, a publicação se torna mais rápida: não depende de um conjunto de artigos para fechamento de um fascículo, mas do processo individual de cada artigo. Por isso, solicitamos o cumprimento dos prazos estipulados.

\section{TAXA DE PUBLICAÇÃO}

Embora as revistas recebam subvenções de instituições públicas, estas não são suficientes para a sua manutenção. Assim, a cobrança de taxa de publicação passou a ser alternativa a fim de garantir os recursos necessários para a produção da RSP.

A RSP em 2016 completou 50 anos de publicação e somente em 2012 iniciou a cobrança de taxa de artigos, fato este imperioso para garantir sua continuidade, sobretudo permitindo-Ihe evoluir com tecnologias mais avançadas, que exigem também maior qualidade e recursos tecnológicos.

O valor cobrado é avaliado regularmente. Assim, para os artigos submetidos a partir de 1 de julho de 2019, o valor da taxa é de $\mathrm{R} \$ 2.400,00$ para artigo original, revisão e comentário, e de $R \$ 1.600,00$ para comunicação breve.

A RSP fornece aos autores os documentos necessários para comprovar o pagamento da taxa perante instituições empregadoras, programas de pósgraduação ou órgãos de fomento à pesquisa.

Após aprovação do artigo, os autores deverão aguardar o envio da fatura proforma com as informações sobre como proceder quanto ao pagamento da taxa. 


\section{a) MODELO DE CARTA DE APRESENTAÇÃO}

Cidade,_[dia]__ de mês de ano.

Prezado Sr. Editor, Revista de Saúde Pública

[Informar os achados e as conclusões mais importantes do manuscrito e esclarecer seu significado para a saúde pública]

[Informar a novidade do estudo]

[Mencionar, se houver, até três artigos publicados pelos autores na linha de pesquisa do manuscrito]

Assim, submetemos à sua apreciação o trabalho

"_[título]__ o qual se encaixa nas áreas de interesse da RSP. A revista foi escolhida [colocar justificativa da escolha da revista para a publicação do manuscrito].

Contribuição dos autores (exemplo): concepção, planejamento, análise, interpretação e redação do trabalho: autor 1 ; interpretação dos resultados e redação do trabalho: autor 2 . Ambos os autores aprovaram a versão final encaminhada.

Certifico que este manuscrito representa um trabalho original e que nem ele, em parte ou na íntegra, nem outro trabalho com conteúdo substancialmente similar, de minha autoria, foi publicado ou está sendo considerado para publicação em outra revista, quer seja no formato impresso ou no eletrônico.

Os autores não possuem conflitos de interesse ao presente trabalho. (Se houver conflito, especificar).

nome completo do autor $1+$ assinatura + ORCID

nome completo do autor $2+$ ORCID

\section{b) DECLARAÇÃo DE RESPONSABILIDADE PELOS AGRADECIMENTOS}

Eu, (nome por extenso do autor responsável pela submissão), autor do manuscrito intitulado (título completo do artigo):

- Certifico que todas as pessoas que tenham contribuído substancialmente à realização deste manuscrito, mas que não preencheram os critérios de autoria estão nomeados com suas contribuições específicas em Agradecimentos no manuscrito.

- Certifico que todas as pessoas mencionadas nos Agradecimentos 
forneceram a respectiva permissão por escrito.

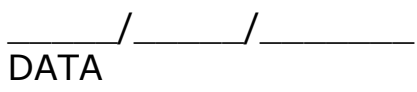

NOME COMPLETO E ASSINATURA

\section{C) DECLARAÇÃO DE TRANSFERÊNCIA DE DIREITOS AUTORAIS}

Concordo que os direitos autorais referentes ao manuscrito [TÍTULO], aprovado para publicação na Revista de Saúde Pública, serão propriedade exclusiva da Faculdade de Saúde Pública, sendo possível sua reprodução, total ou parcial, em qualquer outro meio de divulgação, impresso ou eletrônico, desde que citada a fonte, conferindo os devidos créditos à Revista de Saúde Pública.

Autores:

Local, data

NOME COMPLETO + Assinatura

Local, data

NOME COMPLETO + Assinatura

[Home] [Sobre a revista] [Corpo editorial] [Assinaturas]

(cc) EY Todo o conteúdo do periódico, exceto onde está identificado, está licenciado sob uma Licenca Creative Commons

Avenida Dr. Arnaldo, 715

01246-904 São Paulo SP Brasil

Tel./Fax: +55 11 3061-7985.

revsp@usp.br 